\author{
Abstract-In the Aleutian Islands, \\ patterns of distribution and abun- \\ dance of Pacific ocean perch (Se- \\ bastes alutus) are influenced by \\ oceanographic processes and bio- \\ genic structures. We used general- \\ ized additive modeling (GAM) to ex- \\ amine relationships between these \\ predictors and patterns of settled \\ juvenile and adult distribution and \\ abundance from bottom trawl sur- \\ veys conducted from 1997 through \\ 2010. Depth, temperature, and loca- \\ tion had the greatest influence, and \\ biogenic structures co-occurring with \\ this species improved predictions. \\ Model results confirmed previously \\ reported depth- and temperature- \\ dependent patterns of Pacific ocean \\ Edward A. Laman (contact author) \\ Stan Kotwicki \\ Christopher N. Rooper \\ Email address for contact author: ned.laman@noaa.gov \\ Alaska Fisheries Science Center \\ National Marine Fisheries Service, NOAA \\ 7600 Sand Point Way NE \\ Seattle, Washington 98115
} perch and revealed the elevated presence and abundance of this fish in proximity to Aleutian passes. Adults were more common and abundant in deeper $(\sim 225 \mathrm{~m})$ water than were juveniles $(\sim 150 \mathrm{~m})$, and the probability of encountering either life stage increased in the presence of fan- and ball-shaped sponges over moderate slopes and decreased with increasing tidal velocities. The GAMs accounted for one-quarter of the deviance for juvenile presenceabsence $(24.9 \%)$ and conditional abundance $(25.0 \%)$ and accounted for $38.7 \%$ and $42.5 \%$ of the deviance for the same adult response variables. Although depth, temperature, and location were the dominant predictor variables of both juvenile presence and abundance, our results indicate that biogenic structures that provide vertical structure in otherwise lowrelief, trawlable habitats may represent refugia for Pacific ocean perch juveniles and adults.

Manuscript submitted 18 August 2014. Manuscript accepted 20 April 2015. Fish. Bull. 113:270-289 (2015). Online publication date: 7 May 2015. doi: 10.7755/FB.113.3.4.

The views and opinions expressed or implied in this article are those of the author (or authors) and do not necessarily reflect the position of the National Marine Fisheries Service, NOAA.

\title{
Correlating environmental and biogenic factors with abundance and distribution of Pacific ocean perch (Sebastes alutus) in the Aleutian Islands, Alaska
}

Describing essential fish habitat (EFH), defined by the Magnuson-Stevens Fishery Conservation and Management Act (Magnuson-Stevens Act) as "those waters and substrate necessary to fish for spawning, breeding, feeding or growth to maturity," has been the focus of much recent habitat research. Laidig et al. (2009) used the Delta submersible to conduct visual surveys on the central California shelf and found that demersal fishes associated with boulder and cobble substrata occurred in greater numbers than they did with mud or brachiopod beds. Other studies have observed denser and more diverse assemblages of rockfishes in the presence of increased boulder coverage (Marliave and Challenger, 2009) or in association with rocky ridges (Rooper et al., 2010). Greene et al. (2011) demonstrated that rugged seafloor geomorphologies in southeast Alaska can be used to identify suitable habitat for demersal shelf rockfish (Sebastes spp.). Living substrata can also modify seafloor habitats in ways that impact EFH. Others have considered biogenic structures, such as sponges, corals, and bryozoans, to be important habitat-forming organisms in Alaska (Heifetz et al., 2005; Malecha et al., 2005; Stone et al., 2011) and other waters (e.g., Barthel, 1997 [Weddell Sea]; Beazley et al., 2013 [the northwest Atlantic]; and Coker et al., 2014 [warm-water coral reefs]). In this study, we attempt to add to the growing body of knowledge used to identify and describe EFH for species of Sebastes in Alaska.

The Resource Assessment and Conservation Engineering (RACE) Division of the NOAA Alaska Fisheries Science Center (AFSC) has conducted periodic bottom trawl surveys in the Aleutian Islands since 1980 (von Szalay et al., 2011). These surveys are designed to collect fisheries-independent data on the status and trends of fish and invertebrate species to support formal stock assessments. One of the most abundant commercially harvested species landed from trawl fisheries in the Aleutian Islands is the Pacific ocean perch (Sebastes alutus) (Zenger, 2004; Rooper and Wilkins, 2008; von Szalay et al., 2011), and Pacific ocean perch biomass from this region has been increasing over the last decade 
(Spencer and Ianelli ${ }^{1}$ ). In addition to the commercially harvested species that are one focus of our groundfish surveys, we collect a large amount of biological and physical data that characterize the habitat where these animals are found.

Previous studies have related the distribution and abundance patterns of Pacific ocean perch to physical and biological oceanographic processes in Alaska waters. Logerwell et al. (2005) examined geographic patterns of demersal ichthyofauna in the Aleutian Islands and found that smaller Pacific ocean perch $(\leq 25$ $\mathrm{cm}$, Reuter $\left.{ }^{2}\right)$ inhabited shallower water $(<150 \mathrm{~m})$ than that inhabited by larger individuals, and they further suggested that large catches ( $>100 \mathrm{~kg} / \mathrm{ha}$ ) could be affiliated with zones of increased productivity and prey availability. Other researchers have confirmed that juvenile and adult Pacific ocean perch occur over similar temperature ranges but present different depth distributions (i.e., adults inhabit $>200 \mathrm{~m}$ waters) (Carlson and Haight, 1976; Rooper, 2008).

Epibenthic invertebrates, such as sponges, corals, and bryozoans, are common in the Aleutian Islands (Malecha et al., 2005), where they are collected regularly as part of the AFSC RACE Division bottom trawl surveys (Heifetz et al., 2005). Their extent and diversity also have been noted from submersible and underwater camera studies of the region (Rooper et al., 2007; Stone et al., 2011). Despite their apparent ubiquity in the Aleutian Islands, we presume that these attached sessile invertebrates are patchily distributed in the trawlable areas where RACE bottom trawl surveys are conducted. Mounting evidence indicates that the presence of sponges and corals enhances structural heterogeneity in otherwise low-relief environments and can lead to increases in biodiversity and abundance of associated animals (e.g., Tissot et al., 2006; Beazley et al., 2013; Knudby et al., 2013). The morphological features of these biogenic structures may also serve as refugia for different life stages of commercially harvested species of Sebastes (Freese and Wing, 2003; Rooper and Boldt, 2005; Baillon et al., 2012) and Atka mackerel (Pleurogrammus monopterygius) (Rand and Lowe, 2011) in Alaska waters.

Previous studies have also shown putative associations of rockfishes with sponge, coral, and bryozoan assemblages across a wide range of physical and oceanographic conditions (Love et al., 1991; Rooper and Martin, 2012). Other studies have shown that rockfishes in low-relief, trawlable habitats (e.g., sand or gravel bottom with few boulders or obstructions) tend

\footnotetext{
${ }^{1}$ Spencer, P. D., and J. N. Ianelli. 2010. Assessment of Pacific ocean perch in the Bering Sea/Aleutian Islands. In Stock Assessment and Fishery Evaluation Report for the Groundfish Resources of the Bering Sea/Aleutian Islands Regions, p. 1033-1083. [Available from North Pacific Fishery Management Council, 605 West 4th Ave., Suite 306, Anchorage, AK 99510.]

2 Reuter, R. 2015. Personal commun. Alaska Fish. Sci. Cent., Natl. Mar. Fish. Serv., 7600 Sand Point Way NE, Seattle, WA 98115 .
}

to concentrate near the few boulders or rocky outcrops with attached epibenthic invertebrate communities (e.g., Freese and Wing, 2003; Du Preez and Tunnicliffe, 2011). The Pacific ocean perch has been the focus of several previous studies in Alaska, and there is strong evidence that postsettlement juveniles and adults of Pacific ocean perch are found associated with sponges and corals (Krieger, 1993; Brodeur, 2001; Rooper and Boldt, 2005; Rooper et al., 2007). These studies have not distinguished species of sponges, corals, or bryozoans because of the difficulty in providing consistent identifications. Our study attempts to determine whether the presence or absence of biogenic structures across the broad spectrum of environmental conditions under which they occur affects Pacific ocean perch distribution and abundance.

Consistent field identification of sponges to specific or even generic levels of classification is difficult with the macroscopic techniques available in the field. Adding to the confusion, sponge morphological features, even within a single species, can vary dramatically with environmental conditions, such as current flow and sedimentation rate (Dayton et al., 1974; Bell and Barnes, 2001; Stone et al., 2011), and sponges quickly adapt their morphology to their environment (Palumbi, 1984). Given these challenges, categorizing sponges into groups based on their gross morphology is an attractive alternative. The approach of lumping sponges into groups based on body form has the advantage of eliminating confusion caused by changing and differentially applied systematics and gives us an intuitive link to EFH. In this study, we consider sponge morphology from a functional perspective (the "fish-eye view") of the structure it provides in the habitat. An added benefit of grouping the sponges by this functional morphology is to foster comparability of sponge assemblages among survey years by downplaying the differences in identification attributable to differing levels of expertise among the field biologists.

Sponges and corals are vulnerable to removal or damage by fishing gear (Engel and Kvitek, 1998; Freese et al., 1999; Freese, 2001; Wassenberg et al., 2002; Stone et al., 2011). In addition, these sessile invertebrates are long lived and have limited larval dispersal and reproductive potential (Andrews et al., 2002). As a result, a disturbance resulting in $67 \%$ mortality of sponges or corals would require 20-34 years for these organisms to recover $80 \%$ of their predisturbance biomass (Rooper et al., 2011). Their ecological importance, their vulnerability to damage or removal due to human activities, and their prolonged postdisturbance recovery times have led to the designation of some areas of notable coral and sponge diversity in the Aleutian Islands as "habitat areas of particular concern" under the Magnuson-Stevens Act and to their subsequent closure to fishing (Hourigan, 2009). Gaining greater understanding of the role that biogenic structures play in the distribution and abundance patterns of Pacific ocean perch in the broader context of the oceanographic habitats where they co-occur could prove valuable to 
the ecosystem-based management of this commercially harvested fish.

The primary objective of this study was to describe the distribution and abundance of Pacific ocean perch in relation to physical and biological oceanographic factors across this species' range, on the basis of data from bottom trawl surveys conducted periodically in the Aleutian Islands during the summer. We postulate that biogenic structures (sponges, corals, and bryozoans) can modify Pacific ocean perch distribution and abundance across gradients of environmental and physical conditions by providing additional structural heterogeneity in trawlable habitats where we sample. We used generalized additive modeling (GAM) to identify the physical and biological oceanographic predictor variables that influence the relationships between $\mathrm{Pa}$ cific ocean perch distribution and abundance. We used field observations and out-group comparisons to validate the resulting models.

\section{Materials and methods}

\section{Trawling procedures}

A stratified-random sampling design was used for the AFSC RACE Division Aleutian Islands bottom trawl survey of trawlable areas shallower than the depth of $500 \mathrm{~m}$ across the Aleutian archipelago (Fig. 1). The survey area extends on the north side of the Aleutian island chain from Unimak Pass in the east $\left(165^{\circ} \mathrm{W}\right)$ to Stalemate Bank in the west $\left(170^{\circ} \mathrm{E}\right)$; on the south side of this archipelago, the survey extends from Samalga Pass $\left(170^{\circ} \mathrm{E}\right)$ to Stalemate Bank in the west. Strata are based on 4 depth intervals (1-100 m, 101-200 m, 201$300 \mathrm{~m}$, and 301-500 m) over the continental shelf and upper slope. The depth strata are further segregated by the North Pacific Fisheries Management Council's (NPFMC) Bering Sea Aleutian Islands regulatory area $\left(\mathrm{NPFMC}^{3}\right)$ into survey districts that correspond to the NPFMC subdivisions of western, central, and eastern Aleutian districts and an additional southern Bering Sea survey district that roughly corresponds to the Bogoslof district. Trawl sample allocation in each stratum was achieved with a modified Neyman optimum allocation sampling strategy (Cochran, 1977) to provide representative samples of fishes and invertebrates occurring at each sampling location within each stratum.

Bottom trawl surveys were conducted according to standard protocols established in Stauffer (2004). Our goal was to land each trawl net quickly on the bottom in fishing configuration at a towing velocity of $1.5 \mathrm{~m} / \mathrm{s}(3 \mathrm{kn})$ and to maintain vessel speed, with the net retaining fishing configuration and proper bottom contact for $15 \mathrm{~min}$ (an area of approximately 2.25 ha

${ }^{3}$ NPFMC (North Pacific Fishery Management Council). 2014. Fishery management plan for groundfish of the Bering Sea and Aleutian Islands Management Area, 144 p. NPFMC, Anchorage, AK [Available at website.] was swept on average during each tow). Tables of standard scope ratios of trawl warp in relation to bottom depth were used to reduce potential fishing power differences between the vessels used in different surveys. Date, time, and GPS-generated position were recorded throughout each tow; depth, water temperature, and time of collection also were recorded during each tow with an SBE $39^{4}$ microbathythermograph (Sea-Bird Electronics, Inc., Bellevue, WA). During each tow, the vertical and horizontal trawl openings were measured with Scanmar acoustic net mensuration sensors (Scanmar International, Point Richmond, CA). A bottom contact sensor was attached to the midpoint of the roller gear and was used to measure the degree of contact between the ground gear and the bottom. Trawl hauls were performed during daylight hours (i.e., between $0.5 \mathrm{~h}$ after sunrise and $0.5 \mathrm{~h}$ before sunset), and all trawl performance data were judged after completion through the use of computer-generated graphics and data summaries. For our analyses, we included only catches obtained with satisfactory trawl net performance and bottom contact and only those for which distance fished, net width, bottom depth, and water temperature were recorded.

Data used to parameterize and select the best-fitting GAMs were collected during the periodic bottom trawl surveys of the Aleutian Islands used to assess Pacific ocean perch distribution and abundance. The survey completed in 2000 was the last in a series of triennial surveys. Since 2000, Aleutian Islands bottom trawl surveys have been conducted biennially with the exception of 2008, when insufficient funds led to the cancellation of that year's survey effort. For the surveys undertaken between 1997 and 2010, an average of 394 stations that met our criteria to be included in this study were sampled per year. Total station counts ranged from 355 in 2006 to 413 in 2002 .

\section{Physical variables}

An array of physical, environmental, and spatial predictor variables was used to parameterize the GAMs. At each bottom trawl survey station, start and end positions of the trawl were recorded and bottom depth and temperature were measured. Kriging, a geostatistical procedure that estimates a spatial surface from an array of point values, was used to calculate an index of local bottom slope at each survey station from $100-\mathrm{m}$ bathymetric contour increments between 0 and 2000 $\mathrm{m}$ derived from ETOPO2 gridded elevation data by following the method of Rooper and Martin (2009). Tide velocity $\left(V_{\mathrm{T}}\right)$ was predicted at each sampling station for the date and time of the bottom trawl survey by using tidal prediction software developed at Oregon State University (Tidal Prediction Software [OTPS], website accessed January 2010) (Egbert et al., 1994; Egbert

\footnotetext{
${ }^{4}$ Mention of trade names or commercial companies is for identification purposes only and does not imply endorsement by the National Marine Fisheries Service, NOAA.
} 

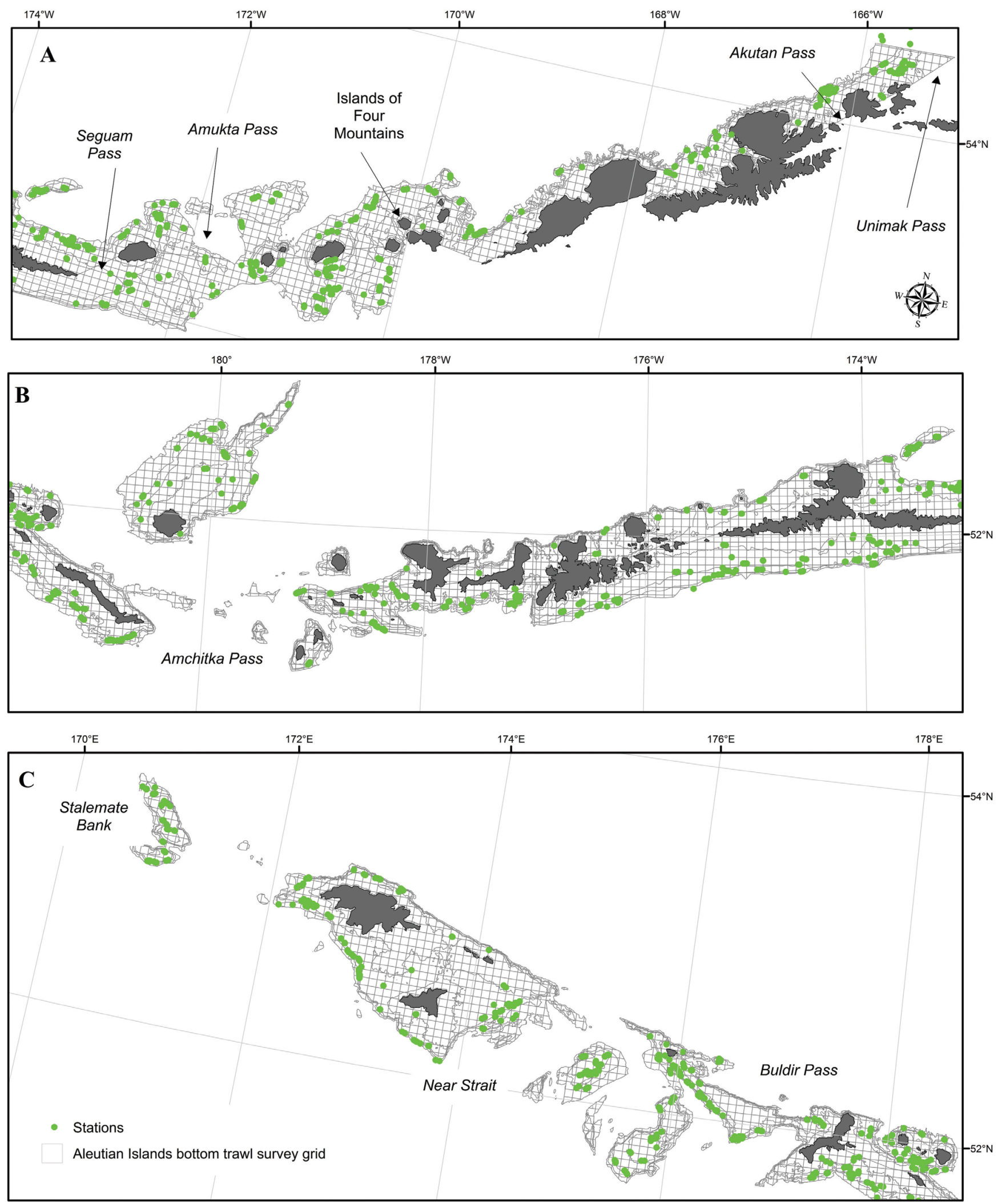

Figure 1

Map of the survey grid and trawl stations of the Alaska Fisheries Science Center Resource Assessment and Conservation Engineering Division Aleutian Islands bottom trawl survey sampled during 1997-2010 in the (A) eastern, (B) central, and (C) western Aleutian Islands. 
and Erofeeva, 2002). To address current-dependent catchability of the bottom trawl, predicted tidal velocity was decomposed into component vectors with velocities parallel or perpendicular to the ship's direction of travel. The difference between the ship's bearing and the direction of tidal flow $\left(\Delta_{\theta}\right)$ was calculated as

$$
\begin{gathered}
\Delta_{\theta} \sim i f\left(\theta_{\mathrm{T}}-\theta_{\mathrm{S}}+360^{\circ}\right)<360^{\circ}, \\
\text { then }\left(\theta_{\mathrm{T}}-\theta_{\mathrm{S}}+360^{\circ}\right), \\
\text { else }\left(\theta_{\mathrm{T}}-\theta_{\mathrm{S}}\right),
\end{gathered}
$$

where $\theta_{\mathrm{T}}=$ the direction of tidal flow; and

$\theta_{\mathrm{S}}=$ the direction of the ship's travel during the trawl survey.

Parallel current $\left(C_{\mathrm{P}}\right)$ was then calculated as

$$
\begin{gathered}
C_{\mathrm{P} \sim} \sim \text { if }\left(90^{\circ}<\Delta_{\theta}<270^{\circ},\right. \\
\text { then }\left(-\sqrt{\frac{v_{\mathrm{T}}^{2}}{1+\left(\tan \left(\Delta_{\theta(\mathrm{r})}\right)\right)^{2}}}\right), \\
\text { else } \sqrt{\frac{v_{T}^{2}}{1+\left(\tan \left(\Delta_{\theta(\mathrm{r})}\right)\right)^{2}}},
\end{gathered}
$$

where $\Delta_{\theta(\mathrm{r})}=$ the angular difference between the direction of tide flow and ship's travel.

Note that $C_{\mathrm{p}}$ carries a negative sign if it is opposite the ship's direction of travel. Because the speed of water flowing through the mouth of the trawl is an important factor that could affect the catch efficiency of the bottom trawl, we estimated trawl velocity at the net mouth $\left(N_{\mathrm{S}}\right)$ as

$$
N_{\mathrm{S}} \sim v_{\mathrm{S}}-C_{\mathrm{p}}
$$

where $v_{\mathrm{S}}=$ the ship's velocity.

Finally, cross current $\left(C_{\mathrm{x}}\right)$ can be estimated as

$$
C_{\mathrm{x}} \sim C_{\mathrm{p}} \tan \left(\Delta_{\theta(r)}\right) \text {. }
$$

Its absolute value $\left(\left|C_{\mathrm{x}}\right|\right)$ was included in the model.

\section{Invertebrate data}

The precision of sponge identification by scientists during the Aleutian Islands bottom trawl surveys has varied over time and remains challenging (Stone et al., 2011). We chose to examine the Aleutian Islands surveys between 1997 and 2010 because, with the advent of waterproof invertebrate field guides for use on deck in 1996 (Kessler $\left.{ }^{5}\right), 1997\left(\operatorname{Clark}^{6}\right)$,

\footnotetext{
${ }^{5}$ Kessler, D. W. 1996. Alaska's saltwater fishes and other sea life. Unpubl. manuscript. Revision by staff of the Alaska Fish. Sci. Cent. Resource Assessment and Conservation Engineering (RACE) Division (for use at sea) of Kessler, D. W. 1985. Alaska's saltwater fishes and other sea life, 358 p. Alaska Northwest Publishing Co., Anchorage, AK.

${ }^{6}$ Clark, R. N. 1997. Invertebrates of the Aleutian Islands, 169 p. Unpubl. manuscript. Alaska Fish. Sci. Cent., Natl. Mar. Fish. Serv., 7600 Sand Point Way NE, Seattle WA 98115.
}

$1999\left(\mathrm{Clark}^{7}\right)$, and $2006\left(\mathrm{Clark}^{8}\right)$, our ability to consistently identify sponges and other invertebrates to higher taxonomic levels in the field was enhanced. As AFSC field biologists have become more familiar with these identification tools, the number of sponge taxa reported from the Aleutian Islands bottom trawl survey has also increased, rising from 7 in 1994 to around 70 in 2006 and 2010. Recently, Stone et al. (2011) recognized 125 unique sponge taxa from the Central Aleutian Islands and indicated that there were likely many more species yet to be described from this region.

Sponges were identified on Aleutian Islands bottom trawl surveys to the lowest possible taxonomic level on the basis of the existing field guides, but identifications depended on the identifier's expertise as well as on the minimum level of identification required that year, both of which varied within and between survey years. The uncertainty in our taxonomic identifications of sponges coupled with our primary aim of considering their contribution to structural heterogeneity in the environment led us to employ Bell and Barnes' (2000) method of grouping sponges by body form into morphological groups (i.e., morphogroups). By combining this technique with a modified version of the list of macroscopical features in Boury-Esnault and Rützler's (1997) thesaurus of sponge morphology, we created 15 morphogroups representing local Aleutian sponge fauna (Fig. 2) and assigned field identified sponges to these groups ex post facto. A group composed of identifiable sponges that did not fit into 1 of the 15 morphogroups (e.g., Plakina tanaga) and unidentifiable fragments of sponges were assigned to a general category entitled "Porifera unidentified."

Corals and bryozoans are epibenthic invertebrates that also provide biogenic structure, which may serve as habitat resources for Pacific ocean perch in this part of their range (Rooper and Boldt, 2005; Rooper et al., 2007; Boldt and Rooper, 2009). To allow comparison with these and similar studies (e.g., Rooper and Martin, 2012), we grouped the coral and bryozoan taxa into single presence-absence composite "corals" and "bryozoans" factors, respectively. Wing and Barnard (2004) included 105 coral species from Alaska waters in their revised field guide. Heifetz et al. (2005) documented 69 taxa of corals in the Aleutian Islands; 25 of them were endemic to the region. For this study, the composite corals factor was composed of members of the orders Alcyonacea, Anthoathecata, Antipatharia, and Scleractinia. From these orders, 99 unique taxa were reported from our catches during the Aleutian Islands bottom trawl surveys conducted between 1997 and 2010. The

\footnotetext{
${ }^{7}$ Clark, R. N. 1999. Gulf of Alaska invertebrates, 100-1000 m, 179 p. Unpubl. manuscript. Alaska Fish. Sci. Cent., Natl. Mar. Fish. Serv., 7600 Sand Point Way NE, Seattle WA 98115.

${ }^{8}$ Clark, R. N. 2006. Field guide to the benthic marine invertebrates of Alaska's shelf and upper slope taken by NOAA/ NMFS/AFSC/RACE Division trawl surveys, 305 p. Unpubl. manuscript. Alaska Fish. Sci. Cent., Natl. Mar. Fish. Serv., 7600 Sand Point Way NE, Seattle WA 98115.
} 
A

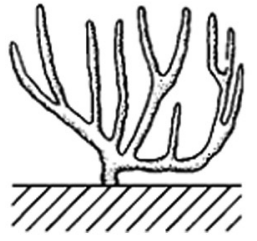

B

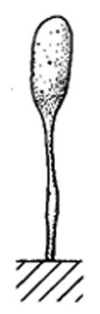

C

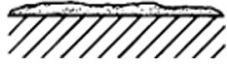

D

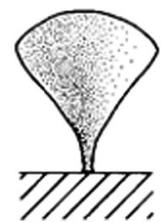

E

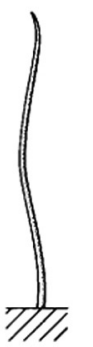

F

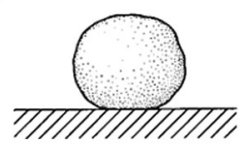

G

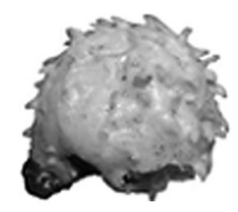

H

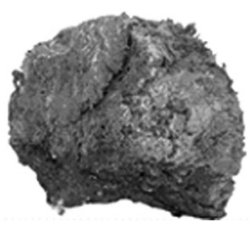

I

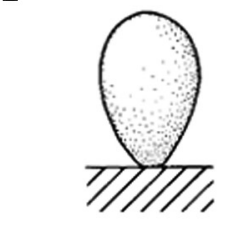

J

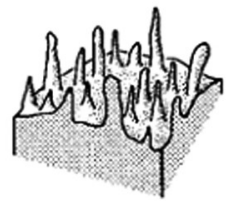

K
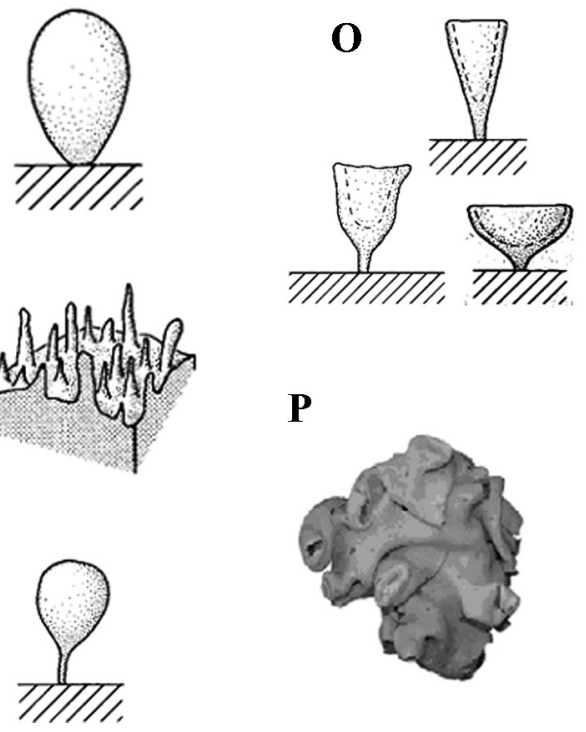

L

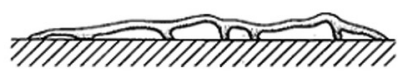

$\mathbf{P}$

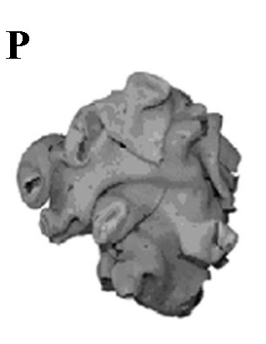

M

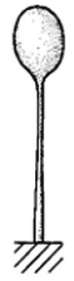

$\mathbf{N}$

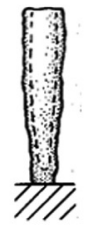

\section{,}

. 


\section{Table 1}

Independent variables that parameterized the generalized additive models used to predict presence, absence, and abundance of Pacific ocean perch (Sebastes alutus). Sponge morphogroups were coded as presence-absence factors ( 1 or 0 , respectively), and the units for continuous variables are temperature $\left({ }^{\circ} \mathrm{C}\right)$, depth $(\mathrm{m})$, local slope $\left({ }^{\circ}\right)$, and for velocity measures $(\mathrm{cm} / \mathrm{s})$. Note that $\mathrm{Sp}$ is a composite term substituted for all sponge morphogroups and $\mathrm{U}$ during model formulation.

\begin{tabular}{ll}
\hline Factors & Continuous variables \\
\hline A=arborescent & $\mathrm{T}=$ temperature \\
$\mathrm{C}=$ clavate & $\mathrm{D}=$ depth \\
$\mathrm{E}=$ =ncrusting & $\mathrm{S}$ =local slope \\
$\mathrm{F}=$ flabellate & Long.=longitude \\
$\mathrm{Fl}=$ flagelliform & $C_{\mathrm{X}}=$ cross current \\
$\mathrm{G}=$ globular & $N_{\mathrm{S}}=$ trawl velocity \\
$\mathrm{Gp}=$ globular-papillate & $V_{\mathrm{T}}=$ tide velocity \\
$\mathrm{M}=$ massive & \\
$\mathrm{O}=$ ovate & \\
$\mathrm{P}=$ papillate & \\
$\mathrm{Pe}=$ pedunculate & \\
$\mathrm{R}=$ repent & \\
$\mathrm{S}=$ stipitate & \\
$\mathrm{Tu}=$ tubular & \\
$\mathrm{V}=$ vase & \\
$\mathrm{U}=$ Porifera unidentified & \\
$\mathrm{Sp}=$ all sponges, composite & \\
$\mathrm{Co}=$ all corals, composite & \\
$\mathrm{Br}=$ all bryozoans, composite &
\end{tabular}

tional scale by dividing individual CPUE estimates by the sum of the annual CPUE within each cruise year; by design, this approach ignored interannual differences in Pacific ocean perch abundance in favor of allowing interannual comparisons during model validation.

\section{Modeling}

Pacific ocean perch distribution and abundance were modeled with the nonparametric regression technique of GAMs (Hastie and Tibshirani, 1986) in R statistical software, vers. 2.13.1 (R Core Development Team, 2011) and the mgcv package (Wood, 2006). This fish species is patchily distributed across our survey area and, typical of field collected data, presents a greater proportion of zero catches than would be expected from a Poisson distribution, resulting in abundance data that are overdispersed (McCullagh and Nelder, 1989). To model these zero-inflated catch data, we followed the recommendation of Barry and Welsh (2002) and undertook independent GAM selection for the Pacific ocean perch presence-absence and conditional abundance data sets. The presence-absence GAMs used a binomial distribution with a logit link function; the conditional abundance models employed a Gaussian distribution with an identity link function.
Probability of presence and conditional abundance of Pacific ocean perch was predicted from GAMs parameterized with a variety of physical, environmental, spatial, and biogenic variables (for a list of these variables and their abbreviations, see Table 1 ). To reduce the tendency of GAMs to over-fit data, we constrained the degrees of freedom ( $\mathrm{df}$ ) for some of the smoothed continuous terms in the models (i.e., $\mathrm{df}=4$ for local slope [Sl], $V_{\mathrm{T}}, C_{x}$, and $N_{s} ; \mathrm{df}=10$ for depth and temperature combined $[\mathrm{D}, \mathrm{T}])$. To identify interdependencies amongst continuous predictor variables we examined Pearson's correlation coefficient ( $r$; Krebs, 1989) for all pairwise comparisons and determined that only depth and temperature were moderately correlated $(|r|=0.55)$. Consequently, we combined depth and temperature into a bivariate interaction term in the GAM. To determine interdependency of sponge morph, bryozoan, and coral presence-absence factors, we computed Pearson's coefficient of mean square contingency ( $\Phi$; Zar, 1984), found that for all pairwise comparisons $|\Phi|$ was $<0.50$, and consequently included each biogenic presence-absence factor as an independent predictor in the GAM.

Four candidate models for the prediction of presence or conditional abundance of juvenile and adult Pacific ocean perch underwent backward stepwise term selection (Weinberg and Kotwicki, 2008; Zuur et al., 2009). The 4 initial model formulations for both of those response variables were

$$
\begin{gathered}
\sim A+C+E+F+F l+G+G p+M+O+ \\
P e+R+S+T u+V+U+C o+B r+ \\
s(\text { Long. })+s(S l)+s\left(N_{\mathrm{S}}\right)+s\left(C_{\mathrm{x}}\right)+s(D, T) \\
\sim A+C+E+F+F l+G+G p+M+O+ \\
\sim+P e+R+S+T u+V+U+C o+B r+ \\
s(\text { Long. })+s(S l)+s\left(V_{\mathrm{T}}\right)+s(D, T), \\
\sim S p+C o+B r+s(\text { Long. })+s(S l)+s\left(N_{\mathrm{S}}\right) \\
+s\left(C_{\mathrm{X}}\right)+s(D, T), \\
\sim S p+C o+B r+s(\text { Long. })+s(S l)+ \\
s\left(V_{\mathrm{T}}\right)+s(D, T) .
\end{gathered}
$$

Formulations 1 and 2 contained the full suite of 18 presence-absence factors for biogenic structures (15 sponge morphogroups [for abbreviations of these factors, see Table 1] and 1 term each for Porifera unidentified [U], all corals, composite [Co], and all bryozoans, composite $[\mathrm{Br}]$ ) as well as the smooth terms longitude (Long.), Sl, and D,T. These model formulations differed by using either (1) the 2 smoothed vector components of $V_{\mathrm{T}}\left(C_{\mathrm{x}}\right.$ and $\left.N_{\mathrm{S}}\right)$ or 2$)$ simply smoothed $V_{\mathrm{T}}$. Formulations 3 and 4 used a reduced predictor variable set by combining all sponges into a single presence-absence term (Sp) and then testing both suites of smooth terms as applied in formulations 1 and 2. Backward stepwise term selection involved fitting each of the 4 formulations above independently with a GAM and then removing the least significant terms iteratively until only significant predictor terms remained. Significance for all models and statistical tests was inferred 
from $P<0.05$. The best-fitting GAMs among the 4 starting models that predicted juvenile or adult presence or abundance were selected on the basis of the lowest Akaike's information criterion scores.

Predicted presence of juvenile and adult Pacific ocean perch, based on the GAMs formulated with data from the period 1997-2010, was validated by comparison with observed presence of this species from the 2012 Aleutian Islands bottom trawl survey. Comparisons were made with Cohen's kappa coefficient ( $k$; Manel et al., 2001), which measures the proportion of correctly predicted cases of presence or absence after accounting for chance effects. This coefficient ranges from 0 to 1 , corresponding with poor to near perfect agreement (Landis and Koch, 1977).

For conditional CPUE models, we used a form of jack-knifing, iteratively leaving out a single year of data, to internally validate the GAM. Residual deviance from each iteration of this cross-validation was used to compute a pseudocoefficient of determination ( $r^{2}$; O'Brien and Rago, 1996) that was used to measure model fit. The residual deviance (RD) is the deviance remaining in the data that is unexplained by the full model (i.e., $\mathrm{RD}=1-r^{2}$ ). By iteratively dropping terms retained in the best-fitting GAM and recalculating $r^{2}$, we were able to assess the relative contribution of that term to the deviance explained by the model, thereby estimating its leverage in the GAM.

\section{Results}

\section{Summary of biological collections}

Between 1997 and 2010, 6 summer bottom trawl surveys were conducted in the Aleutian Islands by AFSC, resulting in a total of 2364 stations included in this study. The Pacific ocean perch was consistently ranked amongst the most abundant fish species collected on these surveys and commonly occurred in the survey catches; they were caught in $58 \%$ of the standard survey tows. Of the trawl catches, $23 \%$ contained juvenile Pacific ocean perch and 53\% contained adults. Juveniles co-occurred with adults in about one-third of the trawl catches $(34 \%)$, and the majority of trawl catches with juveniles also contained adults (79\%). Sponges and corals were common in hauls of the Aleutian Islands bottom trawl surveys as well; they occurred in about $87 \%$ of the trawl catches.

Sponges were the most commonly occurring struc-

\section{Table 2}

Prevalence of biogenic structures, measured as percent frequency of occurrence in trawl tows per annum, in catches of bottom trawl surveys conducted in the Aleutian Islands between 1997 and 2010.

\begin{tabular}{lrrrrrr}
\hline & \multicolumn{5}{c}{ Survey year } \\
\cline { 2 - 7 } Substratum & 1997 & 2000 & 2002 & 2004 & 2006 & 2010 \\
\hline Porifera unidentified & 63 & 78 & 74 & 78 & 78 & 77 \\
Corals & 48 & 51 & 52 & 49 & 50 & 55 \\
Globular-papillate & 43 & 52 & 47 & 46 & 43 & 55 \\
Globular & 43 & 39 & 44 & 39 & 37 & 36 \\
Flabellate & 35 & 37 & 39 & 34 & 34 & 47 \\
Arborescent & 27 & 41 & 34 & 25 & 32 & 35 \\
Massive & 29 & 30 & 25 & 28 & 33 & 38 \\
Papillate & 21 & 30 & 24 & 24 & 37 & 28 \\
Bryozoans & 23 & 32 & 14 & 15 & 13 & 24 \\
Vase & 12 & 14 & 16 & 18 & 14 & 20 \\
Ovate & 10 & 4 & 10 & 13 & 6 & 14 \\
Repent & 0 & 0 & 0 & 4 & 7 & 10 \\
Tubular & 0 & 0 & 2 & 4 & 3 & 4 \\
Encrusting & 0 & 2 & 2 & 4 & 0 & 2 \\
Clavate & 1 & 2 & 1 & 0 & 2 & 0 \\
Flagelliform & 0 & 0 & 1 & 1 & 1 & 0 \\
Stipitate & 0 & 0 & 0 & 0 & 2 & 1 \\
Pedunculate & $<1$ & 0 & $<1$ & 0 & 0 & 0 \\
& & & & & & \\
\hline
\end{tabular}

ture-forming invertebrate collected in our surveys between 1997 and 2010, followed by corals and bryozoans. The majority of the trawl tows selected for analyses contained sponges and corals, which were also present in most of the catches containing Pacific ocean perch (about 91\%). The composite corals group occurred in just over half $(51 \%)$ of the tows in all survey years. Of catches containing juvenile Pacific ocean perch, $96 \%$ also collected sponges or corals, but the rate of co-occurrence for adults was lower (90\%). Bryozoans were less common in our catches than were sponges or corals, occurring, on average, in about $20 \%$ of the trawl hauls. They were also less common in hauls that contained Pacific ocean perch juveniles or adults, occurring in about $20 \%$ of these hauls.

"Porifera unidentified" was the most common sponge category occurring in our survey tows each year (Table 2 ). Globular (G) and globular-papillate (Gp) sponges occur at similar or slightly elevated rates compared with some of the larger morphotypes (e.g., arborescent [A], flabellate $[\mathrm{F}]$, and massive $[\mathrm{M}])$. Clavate $(\mathrm{C})$, encrusting $(\mathrm{E})$, and tubular $(\mathrm{Tu})$ sponges were less common, and pedunculate $(\mathrm{Pe})$ sponges were the rarest morphotype collected.

\section{Summary of environmental and physical data}

Bottom trawl hauls included in this study were conducted over a wide variety of physical and oceanographic conditions. The deepest trawl hauls during the study period were conducted at $488 \mathrm{~m}$ and the shallowest at 


\section{Table 3}

Backward stepwise term selection used in identification of the best-fitting generalized additive models (GAM) for predicting distribution and abundance of Pacific ocean perch (Sebastes alutus) on the basis of data from bottom trawl surveys conducted in the Aleutian Islands during 1997-2010, including the percent contribution of each predictor variable to the deviance explained by the best-fitting model and Akaike's information criterion score (AIC). An asterisk $(*)$ indicates the best-fitting GAM formulation. See Materials and methods section for initial model formulations and Table 1 for definitions of variable abbreviations. CPUE=catch per unit of effort.

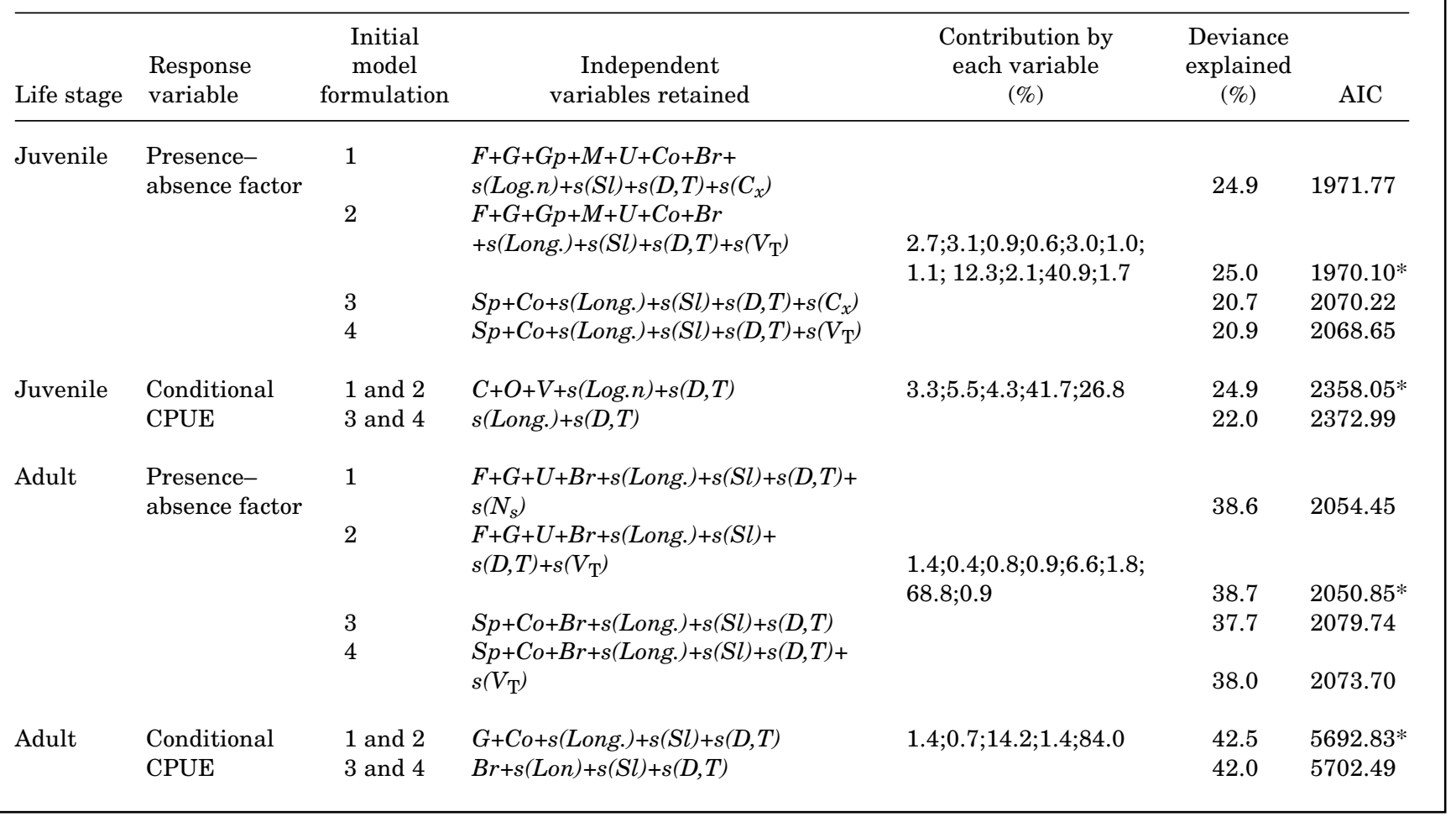

$32 \mathrm{~m}$. Many of the deeper stations are near passes between islands in the Aleutian archipelago, but, in general, deeper stations occur more frequently in the eastern part of the survey area (around Samalga, Amukta, and Seguam passes) than in the west. The values for Sl from the kriged bathymetry at trawl stations ranged from $0^{\circ}$ to $15^{\circ}$. Tidal currents predicted at each bottom trawl haul from the tidal prediction model ranged from $<1 \mathrm{~cm} / \mathrm{s}$ to $\sim 300 \mathrm{~cm} / \mathrm{s}$ (around $3 \mathrm{~m} / \mathrm{s}$ or $6 \mathrm{kn}$ ). The highest current velocities were predicted around Seguam and Amukta passes, and some additional areas of high current were predicted on the east side of Amchitka Pass. Bottom temperatures (T) measured in situ during trawl hauls ranged from $3^{\circ} \mathrm{C}$ to $7^{\circ} \mathrm{C}$.

\section{Results of generalized additive modeling}

Prediction of presence and absence The best-fitting GAMs for predicting the probability of presence of juvenile and adult Pacific ocean perch in the Aleutian Islands accounted for a quarter of the deviance in the juvenile model and $38.7 \%$ of the deviance in the adult model (Table 3 ). The depth distribution of adults, centered around $225 \mathrm{~m}$, was deeper than that of juveniles, found at depths around $150 \mathrm{~m}$. Model effects showed very little dependence on temperature (Figs. 3 and 4). Model responses (GAM effects represented by the solid lines on graphs) indicate increased probability of encountering Pacific ocean perch life stages when $>0$ and decreased probability when $<0$. The standard error generally increases around the predictions for which sample size decreases, signifying areas of lower confidence in the model. Geographically, the predicted odds of collecting either life stage increased at Unimak Pass $\left(165^{\circ} \mathrm{W}\right)$, in the passes near the Islands of Four Mountains $\left(170^{\circ} \mathrm{W}\right)$, in Amukta and Buldir passes $\left(173^{\circ} \mathrm{W}\right.$ and $\left.177^{\circ} \mathrm{E}\right)$, and in Near Strait $\left(175^{\circ} \mathrm{E}\right.$; Figs. 5 and 6$)$. Effects due to local slope were similar for both juveniles and adults and the probabilities of encountering either life stage increased over moderate slopes up to around $5^{\circ}$ of incline.

Increasing tidal velocities initially led to increased probability of encountering adults, but the probability of encounter for juveniles steadily decreased with increasing velocities. The presence of biogenic structures accounted for more of the deviance explained in the juvenile presence-absence model than with the adult model (11.3\% versus $2.6 \%$; Table 3 ). The biogenic struc- 


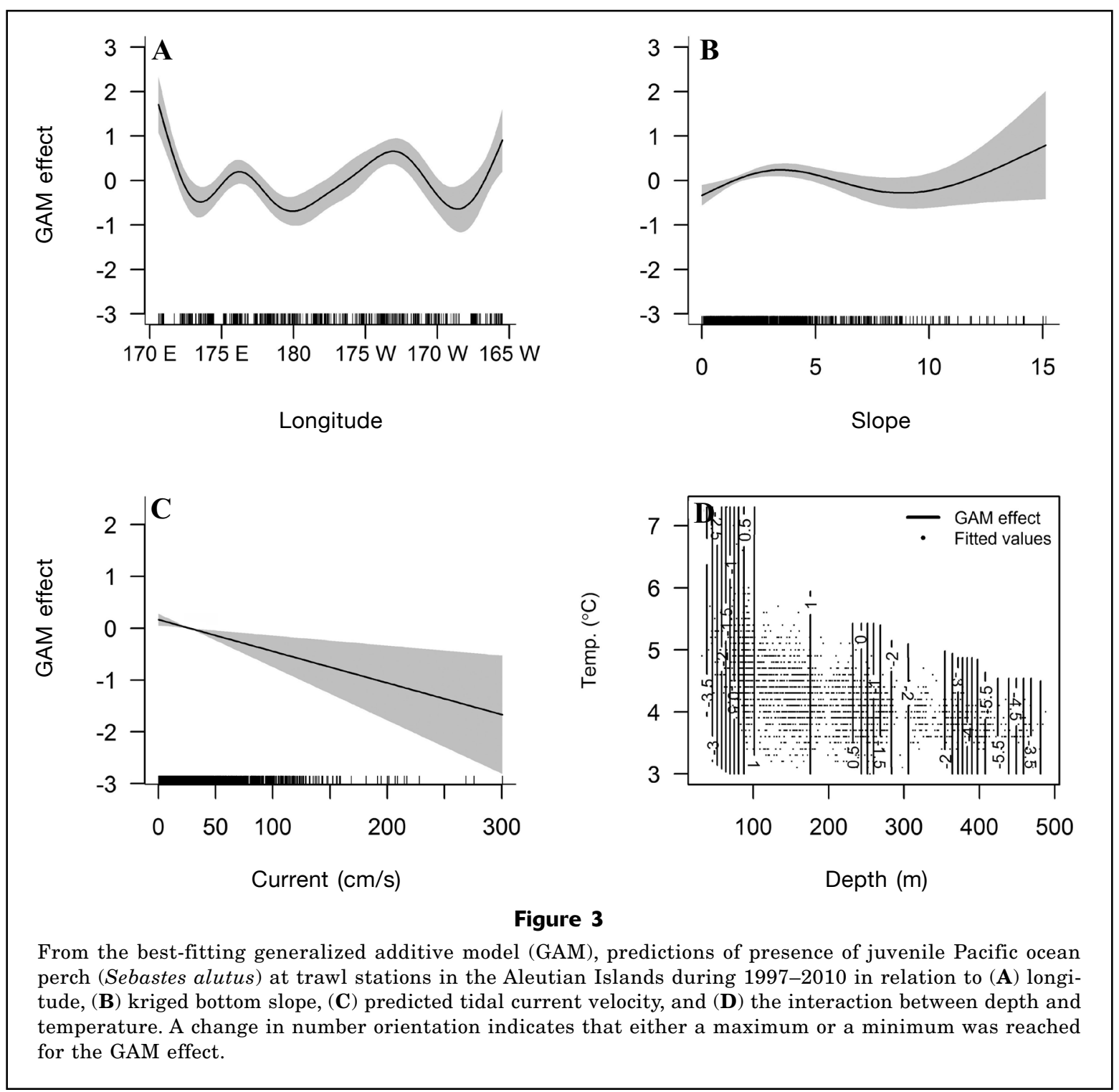

tures retained in the models were either erect forms (e.g., $\mathrm{F}$ or $\mathrm{Co}$ ) or have been reported to be epizoic on erect sponges (e.g., G and Gp sponges; Stone et al., 2011). Although the presence of certain sponge morphogroups and Co was associated with increasing probability of encountering juveniles and adults, the presence of $\mathrm{Br}$ was associated with decreasing probability of encountering either life stage of Pacific ocean perch. This decrease may result from the shallower depth distribution of $\mathrm{Br}$ (depths $<110 \mathrm{~m}$ ) compared with the depth distribution of Pacific ocean perch juveniles (depths $\sim 150 \mathrm{~m}$ ) and adults (depths $\sim 225 \mathrm{~m}$ ). More than half of the deviance explained in each presence-absence GAM was attributable to the $\mathrm{D}, \mathrm{T}$ and Long. terms.

Validation of presence-absence generalized additive modeling The success of the GAMs to predict Pacific ocean perch distribution (presence) varied with life stage
(Figs. 5 and 6). Based on the scale proposed by Landis and Koch (1977) for assessing model performance, the GAM predictions of presence of juvenile Pacific ocean perch from 2012 survey data displayed moderate agreement with trawl observations from the same year $(k=0.52)$. GAM predictions of adult presence were more accurate, showing substantial agreement when predicted presence or absence of adults was compared with observed adult distribution for $2012(k=0.70)$.

Prediction of conditional abundance More deviance in the model was explained by the best-fitting conditional abundance GAM for adults than by the best-fitting GAM for juveniles (Table 3). As with the presence-absence GAMs, the D,T and Long. terms were the most influential predictors of conditional abundance. Unlike the results from the presence-absence GAMs, there were temperature-related optima in both the juvenile 


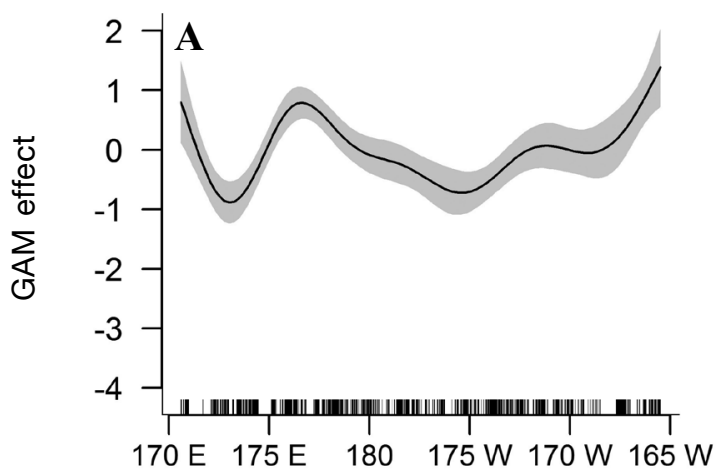

Longitude

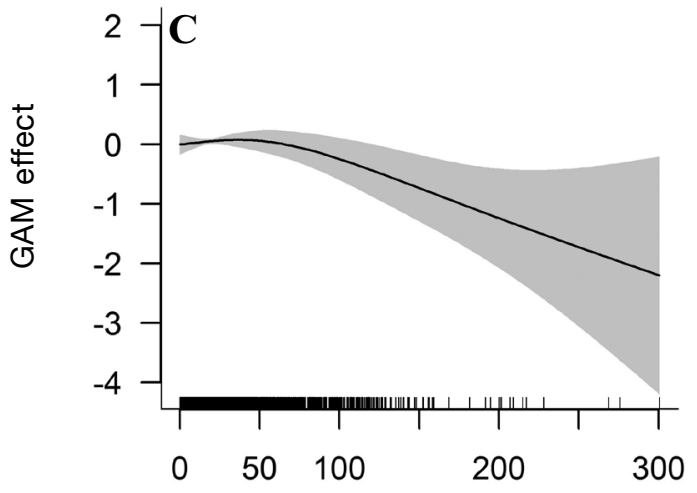

Current $(\mathrm{cm} / \mathrm{s})$

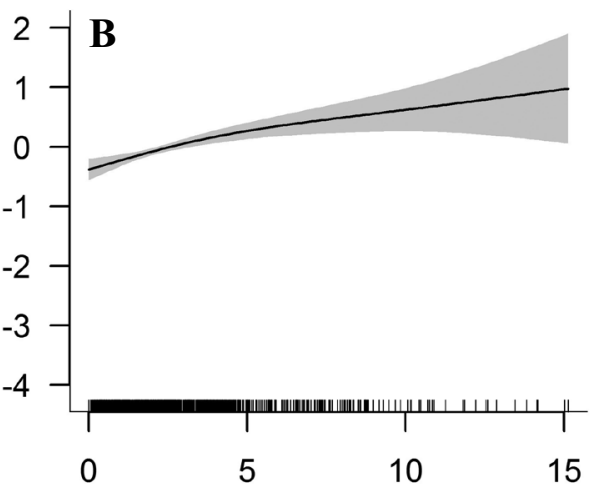

Slope

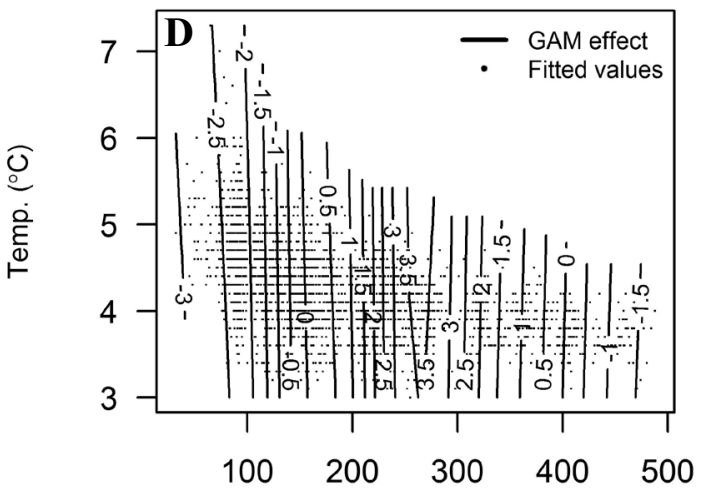

Depth (m)

Figure 4

From the best-fitting generalized additive model (GAM), predictions of presence of adult Pacific ocean perch (Sebastes alutus) at trawl stations in the Aleutian Islands during 1997-2010 in relation to (A) longitude, (B) kriged bottom slope, (C) predicted tidal current velocity, and (D) the interaction between depth and temperature. A change in number orientation indicates that either a maximum or a minimum was reached for the GAM effect.

and adult conditional abundance GAMs (Figs. 7 and 8). Similar D,T-dependent optima were observed for juvenile and adult Pacific ocean perch abundance where present, and predicted conditional abundance was highest over depths of 200-250 $\mathrm{m}$ and a temperature range of $4.5-5.0^{\circ} \mathrm{C}$. As with the predictions of increased probability of occurrence from the presence-absence GAMs, some of the highest predicted conditional abundances for either life stage are associated with major Aleutian passes. Higher abundances were predicted around Buldir Pass $\left(176^{\circ} \mathrm{E}\right)$ and Seguam Pass $\left(173^{\circ} \mathrm{W}\right)$, and some decreased abundances were predicted around the Islands of Four Mountains $\left(170^{\circ} \mathrm{W}\right)$. Predicted adult conditional abundance increased with increasing Sl, up to an incline of around $5^{\circ}$, but Sl was not a predictor retained in the juvenile conditional abundance GAM.

Fewer biogenic structures were retained in the bestfitting conditional abundance GAMs, than in the pres- ence-absence GAMs, but the relative contribution of these predictors to the deviance explained in the model was similar within each life stage (Table 3 ). The combined deviance explained by the presence or absence of biogenic structures remained a more important proportional contributor to the total deviance explained in the juvenile conditional abundance GAM than in the adult GAM (13.1\% versus $2.1 \%)$. When sponges of the $\mathrm{C}$ and $\mathrm{V}$ morphogroups were present, the predicted juvenile conditional abundance was higher, but the presence of sponges of the ovate [O] morphogroup was associated with a decrease in the abundance of juveniles where present. For adults, conditional abundance increased in the presence of Co and decreased in the presence of sponges of the $\mathrm{G}$ morphogroup.

Validation of conditional abundance generalized additive modeling By cross-validating our GAM predictions it- 

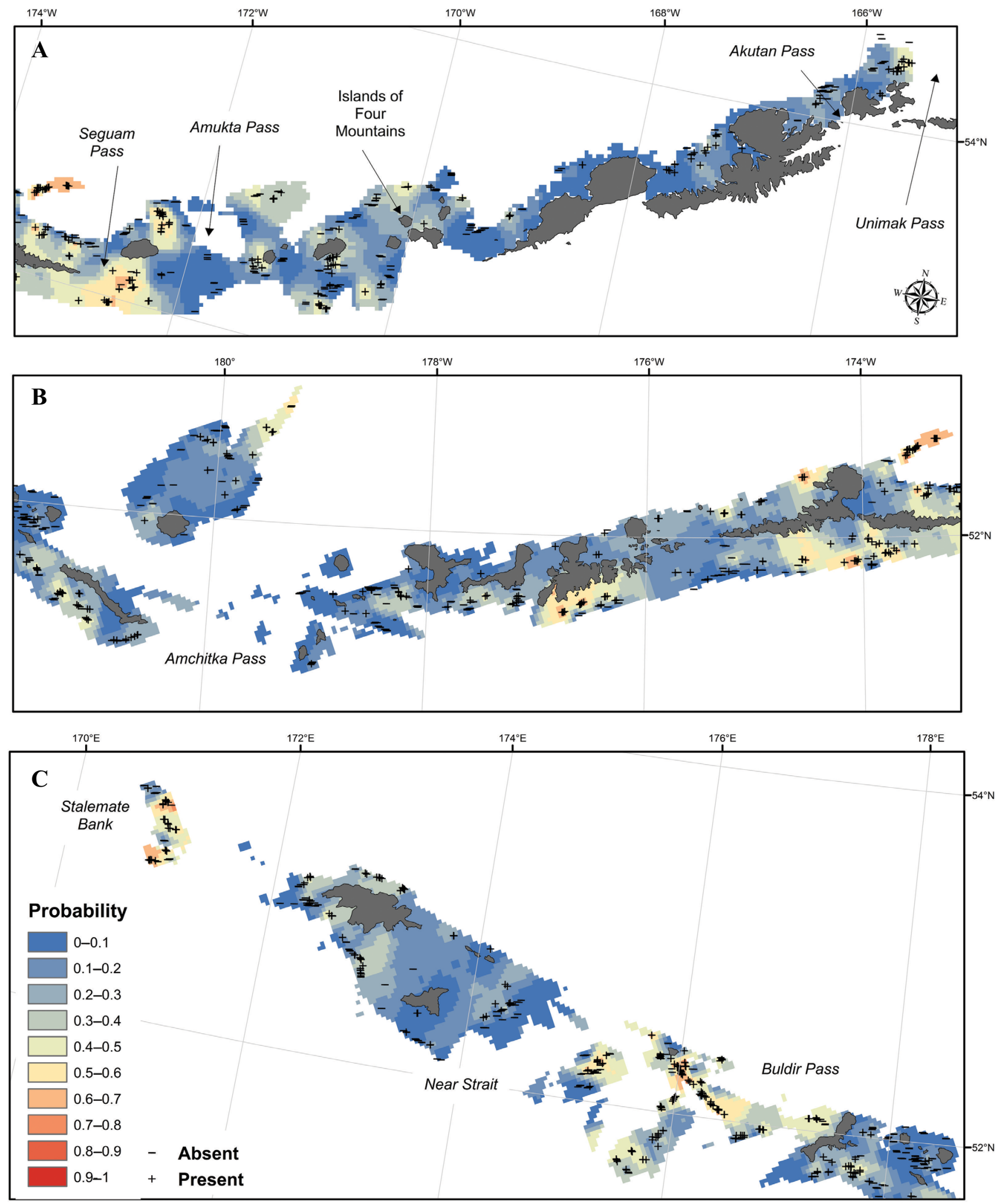

Figure 5

Observed (symbols) and predicted (shaded) presence or absence of juvenile Pacific ocean perch (Sebastes alutus) over an inverse distance-weighted surface from a generalized additive model based on Aleutian Islands bottom trawl surveys conducted during 1997-2010 across the (A) eastern, (B) central, and (C) western Aleutian Islands. 

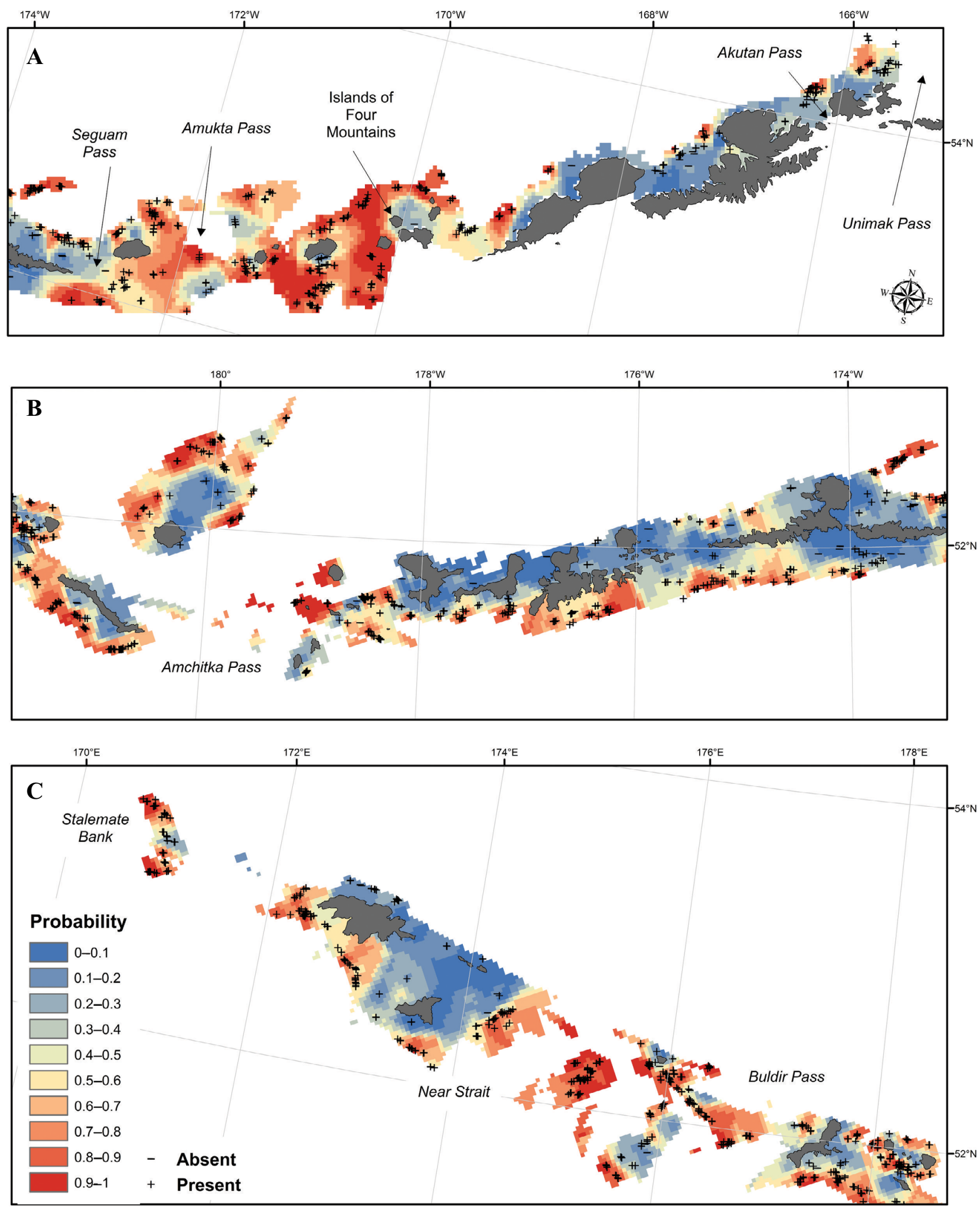

Figure 6

Observed (symbols) and predicted (shaded) presence or absence of adult Pacific ocean perch (Sebastes alutus) over an inverse distance-weighted surface from a generalized additive model based on Aleutian Islands bottom trawl surveys conducted during 1997-2010 across the (A) eastern, (B) central, and (C) western Aleutian Islands. 


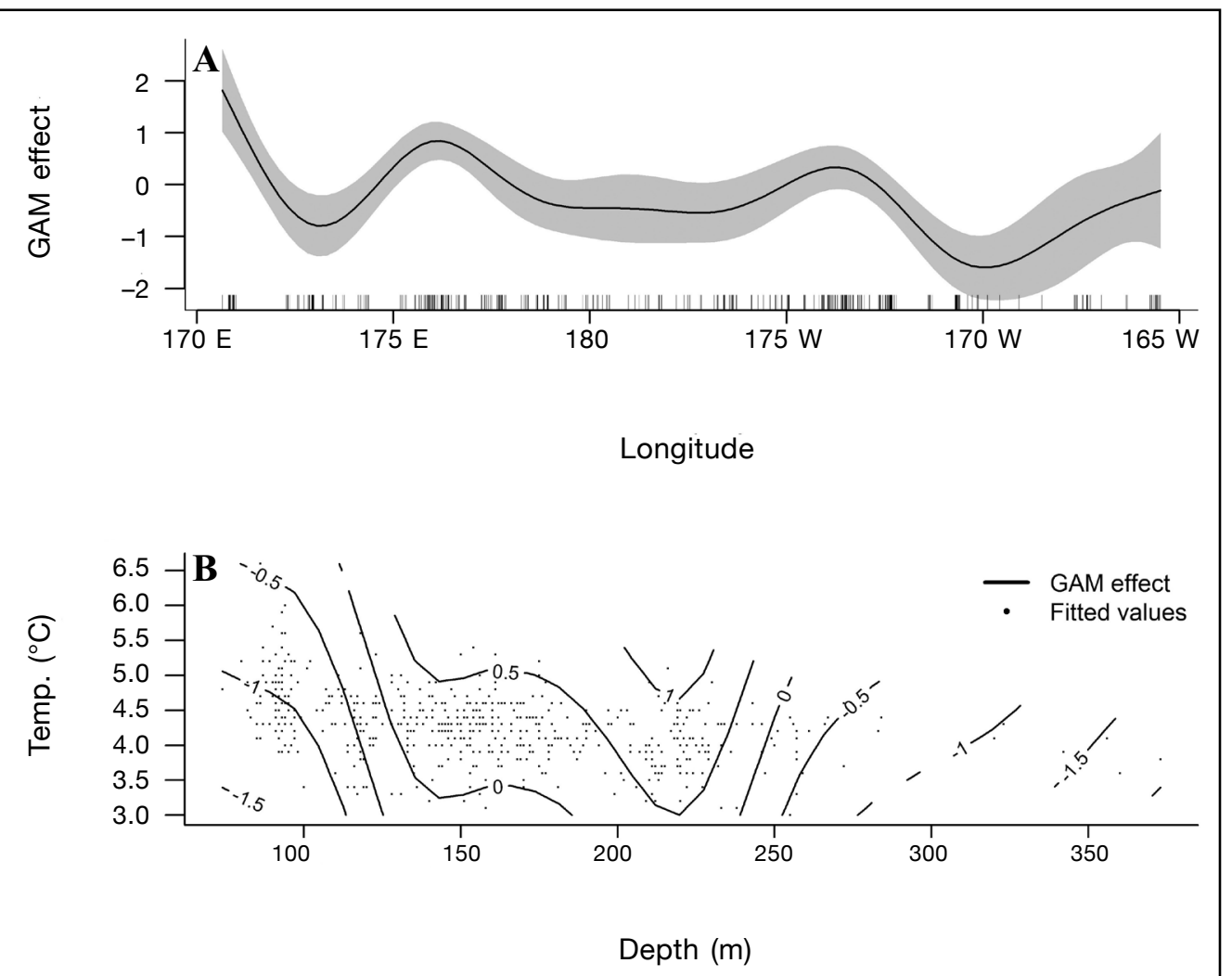

Figure 7

From the best-fitting generalized additive model (GAM), predictions of conditional abundance (scaled, normalized CPUE where present) of juvenile Pacific ocean perch (Sebastes alutus) at trawl stations in the Aleutian Islands during 1997-2010 in relation to (A) longitude and (B) the interaction between depth and temperature. A change in number orientation indicates that either a maximum or a minimum was reached for the GAM effect.

eratively against excluded years, we showed that the conditional abundance GAMs did a fair job of predicting juvenile Pacific ocean perch abundance and a better job for adults than for juveniles. The deviance explained in each of the jack-knifed cross-validations ranged from $23.2 \%$ to $28.5 \%$ for juveniles and from $41.4 \%$ to $44.8 \%$ for adults. Examination of diagnostic plots and residuals indicated that model assumptions were met.

\section{Discussion}

Depth, temperature, and proximity to major Aleutian passes (D,T and Long., respectively) were dominant influences in our GAMs (i.e., accounted for the greatest proportion of the deviance explained) and operated over broad spatial scales. These effects compared favorably with similar findings of other researchers by confirming the depth distributions and temperature affiliations of Pacific ocean perch life stages (Carlson and Haight, 1976; Brodeur, 2001; Love et al., 2002; Rooper and Boldt, 2005; Rooper 2008). The GAMs predicted in- creases of occurrence and abundance of Pacific ocean perch in proximity to most major Aleutian passes (e.g., Amukta, Seguam, and Buldir) that were similar to findings by Logerwell et al. (2005). We also determined that the inclusion of predictors that act over more local scales (e.g., biogenic structures and slope of the bottom at a sampling station) can improve the GAM fit and enhance our understanding of Pacific ocean perch distribution and abundance patterns within the context of broader scale oceanographic processes.

Logerwell et al. (2005) concluded that patterns of demersal fish distribution and abundance could reflect proximity to biological "hot spots," where prey aggregations form and productivity increases because of the convergence of bathymetric and hydrographic processes, such as those observed near Aleutian passes. There is substantial tidal mixing in the passes (Ladd et al., 2005), and the dominant flow of water through them is from the south to the north (Stabeno et al., 1999). The tidal mixing, the persistent northward water movement, and the interaction of mixed water with the euphotic zone near these passes often create local 


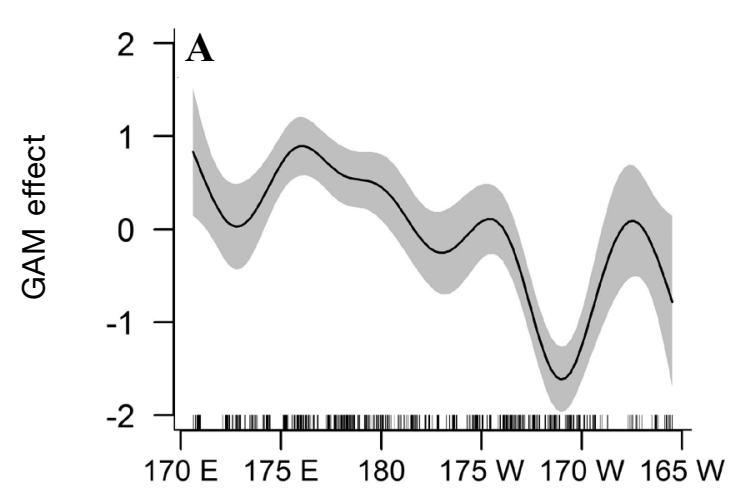

Longitude

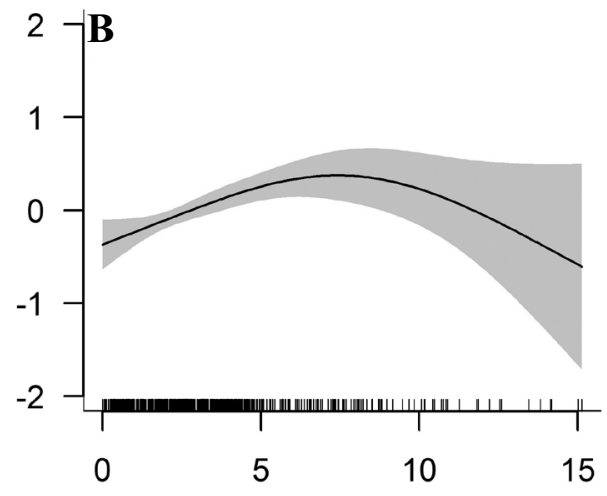

Slope

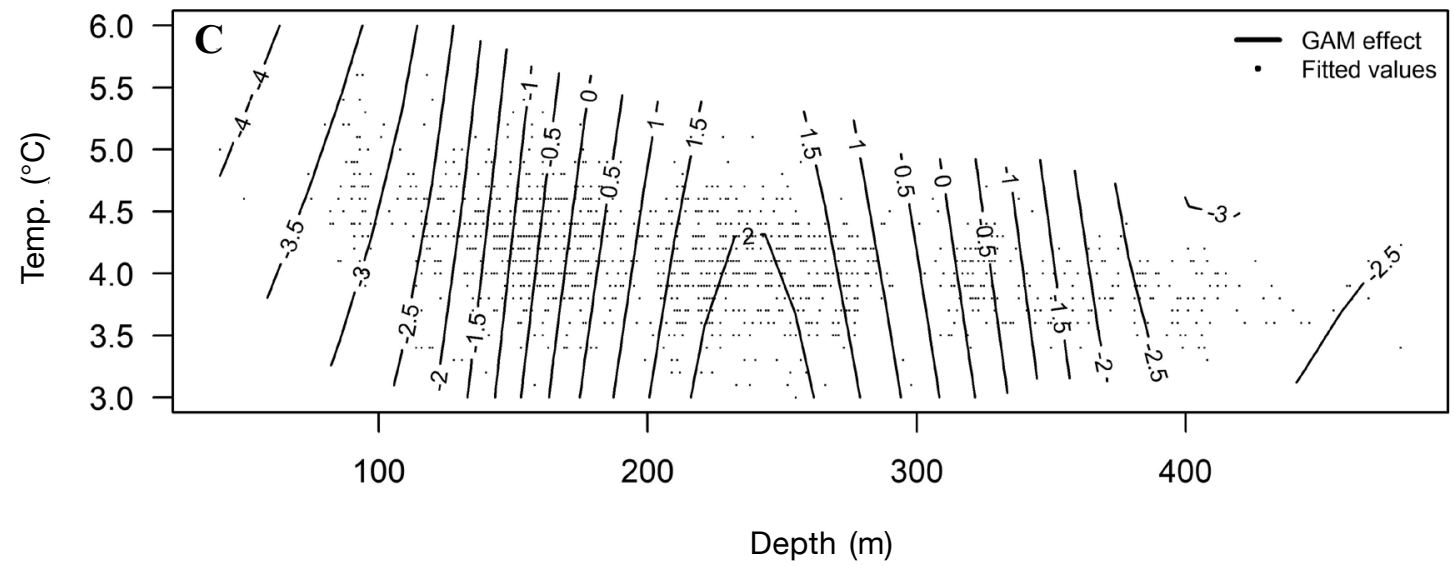

Figure 8

From the best-fitting generalized additive model (GAM), predictions of conditional abundance (scaled, normalized CPUE where present) of adult Pacific ocean perch (Sebastes alutus) at trawl stations in the Aleutian Islands during 1997-2010 in relation to (A) longitude, (B) kriged bottom slope, and (C) the interaction between depth and temperature. A change in number orientation indicates that either a maximum or a minimum was reached for the GAM effect.

regions of high production, especially to the north of the passes (Ladd et al., 2005). In addition, upwelling can occur around passes and may enhance local production (Swift and Aagaard, 1976; Coyle, 2005), leading to potentially greater abundance of the zooplankton prey of Pacific ocean perch (Carlson and Haight, 1976; Brodeur, 1983; Boldt and Rooper, 2009). Southward currents that flow through Aleutian passes typically flow down the western side of the pass, whereas northward flow occurs on the eastern side (Stabeno et al., 2005). Because the dominant current along the south side of the Aleutian chain is to the west and the dominant current along the north side is to the east, larval retention zones could exist near passes (Stockhausen and Hermann, 2007). Genetic studies of Pacific ocean perch in other areas have indicated that stock structure on a small scale (70-400 km) may occur and could be the result of limited dispersal of early life stages (Seeb and Gunderson, 1988; Withler et al., 2001; Palof et al., 2011). The possibility for high productivity and larval retention around Aleutian passes, combined with the potential natural barriers to migration of Pacific ocean perch along the archipelago (e.g., predominant currents as well as deeper passes in the western Aleutian Islands), could further explain our results that indicate increases in presence and abundance near Aleutian passes.

The structural heterogeneity created in trawlable habitats by the presence of sponges, corals, and bryozoans presumably provides refugia from predation and shelter from currents for juvenile Pacific ocean perch (Stoner, 1982; Ryer, 1988; Ryer et al., 2004) and recently has been shown to provide nursery habitat for redfish larvae (Sebastes spp.) around sea pens (Baillon 
et al., 2013). Juvenile Pacific ocean perch have been observed in close association with sponges and corals on the bottom (Carlson and Straty, 1981; Rooper et al., 2007) and appear to favor more spatially heterogeneous habitats (Du Preez and Tunnicliffe, 2011). Adult Pacific ocean perch are known to form schools on or near the seafloor (Krieger, 1993; Brodeur, 2001; Hanselman et al., 2012) where we typically collect them over areas of softer seafloor substrata, such as sand or gravel, during our surveys. Adults have been observed in association with sea whip forests (Brodeur, 2001), although they appear, on the basis of our model results, to be less benthically oriented than juveniles. The apparent affiliation of Pacific ocean perch with biogenic structures over trawlable habitats in the Aleutian Islands could potentially modify their distribution and abundance patterns on a local scale within the context of the broadly acting biological and oceanographic processes that determine larger scale patterns.

All our models retained biogenic structures with morphological features capable of increasing structural heterogeneity in the otherwise low-relief, trawlable habitats, but none retained the $\mathrm{Sp}$ predictor, the presence-absence factor compositely representing all sponges. Most of the sponges and corals retained in our models are erect forms (e.g., $\mathrm{V}$ and $\mathrm{F}$ sponges and primnoid corals), but even the nonerect forms (e.g., G and Gp sponges) are known to be epizoic on larger, erect sponge forms (Stone et al., 2011). In previous studies that showed associations of Sebastes species (Heifetz, 2002; Krieger and Wing, 2002; Du Preez and Tunnicliffe, 2011) and Pacific ocean perch (Rooper and Boldt, 2005; Rooper et al., 2007) with sponges and corals, the epibenthic invertebrates were considered composite categories. The results of our study refine our understanding of the relationship between Pacific ocean perch distribution and abundance and the structural heterogeneity provided by biogenic structures from these larger composite groupings. Our results indicate that habitat heterogeneity, and vertical relief in particular, can affect Pacific ocean perch distribution and abundance.

Although studies have indicated that the presence of structure-forming epibenthic invertebrates can lead to enhanced abundance and biodiversity of associated animals (e.g., Du Preez and Tunnicliffe, 2011; Beazley et al., 2013; Knudby et al., 2013), Tissot et al. (2006) concluded that associations of fishes with sponges and corals do not necessarily imply functional relationships between these groups of organisms. The co-occurrences between Pacific ocean perch and biogenic structures that we modeled in the Aleutian Islands may derive from facultative relationships (e.g., structural refugia and prey availability) or could simply result from a convergence of conditions that favor the presence of both the fish and epibenthic invertebrates. The underlying mechanisms leading to the patterns observed in our study are an important area for future study.

Generalized additive models relate response variables to dependent model variables through additive and unrestrictive smooth functions, making them well suited for modeling typical interactions of species with environment (Hastie and Tibshirani, 1986; Maravelias, 2001; Guisan et al., 2002). The GAMs also provide a data-defined assessment of the shape of the response of a species to independent variables (Maravelias and Papaconstantinou, 2003). The anticipated nonlinear relationships of Pacific ocean perch distribution and abundance with their environment made GAMs well suited to provide a tool that was more informative than traditional regression techniques.

One drawback to the use of GAMs is that they can over-fit the data, resulting in unrealistic models with limited predictive power (Kim and Gu, 2004; Wood, 2006). To minimize the risk of over-fitting, we constrained the df available to smoothed continuous predictor variables in the model and successfully validated our GAM predictions of juvenile and adult presence with a data set external to the modeling effort (i.e., the data from the 2012 Aleutian Islands trawl survey). We conclude that the GAMs parameterized in this study were fairly accurate predictors of juvenile occurrence but were better at predicting adult occurrence. Furthermore, our validation results indicate that these models were robust predictors of the distribution and abundance of Pacific ocean perch juveniles and adults in the Aleutian Islands in subsequent years.

Our approach of modeling presence and absence and conditional abundance independently is a technique intended to cope with zero-inflated and over-dispersed data and that is common to abundance surveys (McCullagh and Nelder, 1989; Barry and Welsh, 2002). Processes that influence distribution and those that affect abundance do not have to be the same. By modeling the 2 response variables independently, we were able to determine that the models for Pacific ocean perch distribution and conditional abundance shared more in common than not. For example, the best-fitting models for both life stages across both model classes all share the $\mathrm{D}, \mathrm{T}$ and Long. terms in common, but for the presence-absence GAMs adults and juveniles also share the $\mathrm{Sl}$ and $V_{\mathrm{T}}$ terms. By comparison, there is no overlap in the suite of biogenic structures retained in the juvenile presence-absence and conditional abundance GAMs, a result that may indicate that the local conditions leading to enhanced probability of encountering juvenile Pacific ocean perch in our trawl tows are not the same as those leading to increased abundance when this species is present.

There is ample evidence that rockfishes occur commonly in areas that are untrawlable with our present net (Carlson and Haight, 1976; Zimmermann, 2003; Rooper et al., 2007; Rooper et al., 2011). Underwater camera and submersible observations indicate that some untrawlable areas are havens for biogenic structures and fishes (Rooper et al., 2007; Stone et al., 2011). In some instances, catch rates for Pacific ocean perch varied with tidal velocity (i.e., juvenile and adult occurrence). Changing catch rates could result from tidal current regimes that affect distribution and abundance 
of Pacific ocean perch directly (e.g., currents that exceed swimming speeds) or indirectly by impacting biogenic structures that would otherwise provide refugia from currents (e.g., physical removal of structures in high current areas or their morphological adaptation to differing local current or sedimentation regimes). We hope to use in situ observation of current speeds and fish behavior (e.g., optical sampling) over trawlable and untrawlable bottom in the future, along with direct measurements of water velocity into the net mouth, to try and elucidate some of the potential mechanisms of this phenomenon and to improve the predictive power of these models.

We were not able to account for all of the variables that may influence the distribution and abundance of Pacific ocean perch in the Aleutian Islands. Among these variables were the availability of prey and the substrate type at each bottom trawl survey station. Both of these factors are known to influence the distribution and abundance of rockfishes (Carlson and Straty, 1981; Pearcy et al, 1989; Matthews, 1990; Love et al., 1991; Stein et al., 1992; Krieger and Ito, 1999; Yoklavich et al., 2000; Boldt and Rooper, 2009). Pacific ocean perch feed primarily on copepods and euphasiids both as juveniles and adults (Carlson and Haight, 1976; Brodeur, 1983; Boldt and Rooper 2009), and the success of these predator-prey interactions is concentration dependent and partly mediated by the availability of light that enables a fish to locate its prey. Water column light (irradiance) profiles vary widely across the Aleutian Islands (senior author, unpubl. data). Fish species are known to change their behavior in response to changing ambient light levels (e.g., Ryer and Olla, 1999; Kotwicki et al., 2009). The amount and spectral range of the available light in the water column may be another important component of EFH for fish with visually mediated behaviors (Sathyendranath and Platt, 1990). Incorporating irradiance and spectral quality of light as habitat parameters in future models will provide new insights into delineating fish habitats.

Effective management of fish populations and fishing activities requires better knowledge of the functional relationships between fish species and their habitats. In the case of Pacific ocean perch, we have concluded from this study that the species occurs predictably within certain depth ranges, in certain areas, and that they can be associated with erect forms of sponges and corals. In the Aleutian Islands, fishing activities can affect benthic habitats by causing damage and mortality to sponges and corals. A number of studies have shown that recovery times for sponges and corals damaged by bottom trawling or natural phenomena could be on the order of decades to centuries (Freese et al., 1999; Andrews et al., 2002; Rooper et al., 2011). Diagnosing the relationships between commercially important fish species and biogenic structures vulnerable to damage from human activity will be useful for management decisions to balance habitat protection and commercial fishing opportunities.

\section{Acknowledgments}

The authors thank the captains, fishermen, and scientific staff who spent many hours at sea conducting these surveys. We thank D. Somerton, W. Palsson, K. Mier, J. Orr, and the anonymous reviewers for their time and effort that greatly improved this manuscript. In addition, we are indebted to M. Martin, L. Britt, and R. Harrison for their insightful and often lively discussions that helped us maintain our perspective.

\section{Literature cited}

Andrews, A. H., E. E. Cordes, M. M. Mahoney, K. Munk, K. H. Coale, G. M. Cailliet, and J. Heifetz.

2002. Age, growth and radiometric age validation of a deep-sea, habitat-forming, gorgonian (Primnoa resedaeformis) from the Gulf of Alaska. Hydrobiologia 471:101-110. Article

Baillon, S., J. Hamel, V. Wareham, and A. Mercier.

2012. Deep cold-water corals as nurseries for fish larvae. Front. Ecol. Environ. 10:351-356. Article

Barry, S. C., and A. H. Welsh.

2002. Generalized additive modelling and zero inflated count data. Ecol. Model. 157:179-188. Article

Barthel, D.

1997. Fish eggs and pentacrinoids in Weddell Sea hexactinellids: further examples for the structuring role of sponges in Antarctic benthic ecosystems. Polar Biol. 17(1):91-94. Article

Beazley, L. I., E. L. Kenchington, F. J. Murillo, and M. del Mar Sacau.

2013. Deep-sea sponge grounds enhance diversity and abundance of epibenthic megafauna in the Northwest Atlantic. ICES J. Mar. Sci. 70:1471-1490. Article

Bell, J. J., and D. K. A. Barnes.

2000. The influences of bathymetry and flow regime upon the morphology of sublittoral sponge communities. J. Mar. Biol. Assoc. U.K. 80:707-718. Article

2001. Sponge morphological diversity: a qualitative predictor of species diversity? Aquat. Conserv.: Mar. Freshw. Ecosyst. 11:109-121. Article

Boldt, J. L., and C. N. Rooper.

2009. Abundance, condition, and diet of juvenile $\mathrm{Pa}$ cific ocean perch (Sebastes alutus) in the Aleutian Islands. Fish. Bull. 107:278-285.

Boury-Esnault, N., and K. Rützler (eds.).

1997. Thesaurus of sponge morphology. Smithson. Contrib. Zool. 596, 59 p. Smithsonian Inst. Press, Washington, D.C. Article

Brodeur, R. D.

1983. Food habits, dietary overlap and gastric evacuation rates of rockfishes (genus Sebastes). M. S. thesis, 96 p. Oregon State Univ., Corvalis, OR. [Available at website.]

2001. Habitat-specific distribution of Pacific ocean perch (Sebastes alutus) in Pribilof Canyon, Bering Sea. Cont. Shelf Res. 21:207-224.

Carlson, H. R., and R. E. Haight.

1976. Juvenile life of Pacific ocean perch (Sebastes alutus) in coastal fjords of southeastern Alaska: their environment, growth, food habits, and schooling behavior. Trans. Am. Fish. Soc. 105:191-201. Article 
Carlson, H. R., and R. R. Straty.

1981. Habitat and nursery grounds of Pacific rockfish, Sebastes spp., in rocky coastal areas of southeastern Alaska. Mar. Fish. Rev. 43(7):13-19.

Chikuni, S.

1975. Biological study on the population of the Pacific ocean perch in the North Pacific. Bull. Far Seas Fish. Res. Lab. 12:1-119.

Cochran, W. G.

1977. Sampling techniques, $3^{\text {rd }}$ ed., 428 p. John Wiley \& Sons, Inc., New York.

Coker, D. J., S. K. Wilson, and M. S. Pratchett.

2014. Importance of live coral habitat for reef fishes. Rev. Fish Biol. Fish. 24:89-126. Article

Coyle, K. O.

2005. Zooplankton distribution, abundance and biomass relative to water masses in eastern and central Aleutian Island passes. Fish. Oceanogr. 14(suppl. 1):77-92. Article

Dayton, P. K., G. A. Robilliard, R. T. Paine, and L. B. Dayton. 1974. Biological accommodation in the benthic community at McMurdo Sound, Antarctica. Ecol. Monogr. 44:105-128. Article

Du Preez, C., and V. Tunnicliffe.

2011. Shortspine thornyhead and rockfish (Scorpaenidae) distribution in response to substratum, biogenic structures and trawling. Mar. Ecol. Prog. Ser. 425:217-231. Article

Egbert, G. D., A. F. Bennett, and M. G. G. Foreman.

1994. TOPEX/POSEIDON tides estimated using a global inverse model. J. Geophys. Res. 99:2482124852. Article

Egbert, G. D., and S. Y. Erofeeva.

2002. Efficient inverse modeling of barotropic ocean tides. J. Atmos. Ocean. Technol. 19:183-204. Article

Engel, J., and R. Kvitek.

1998. Effects of otter trawling on a benthic community in Monterey Bay National Marine Sanctuary. Conserv. Biol. 12:1204-1214. Article

Freese, J. L.

2001. Trawl-induced damage to sponges observed from a research submersible. Mar. Fish. Rev. 63(3):7-13.

Freese, L., P. J. Auster, J. Heifetz, and B. L. Wing. 1999. Effects of trawling on seafloor habitat and associated invertebrate taxa in the Gulf of Alaska. Mar. Ecol. Prog. Ser. 182:119-126. Article

Freese, J. L., and B. L. Wing.

2003. Juvenile red rockfish, Sebastes sp., associations with sponges in the Gulf of Alaska. Mar. Fish. Rev. 65(3):38-42.

Greene, G. H., V. M. O'Connell, and C. K. Brylinsky.

2011. Tectonic and glacial related seafloor geomorphology as possible demersal shelf rockfish habitat surrogatesExamples along the Alaskan convergent transform plate boundary. Cont. Shelf Res. 31:S39-S53. Article

Guisan, A., T. C. Edwards, Jr., and T. Hastie.

2002. Generalized linear and generalized additive models in studies of species distributions: setting the scene. Ecol. Model. 157:89-100. Article

Hanselman, D. H., P. D. Spencer, D. R. McKelvey, and M. H. Martin.

2012. Application of an acoustics-trawl survey design to improve estimates of rockfish biomass. Fish. Bull. 110:379-396.
Hastie, T., and R. Tibshirani.

1986. Generalized additive models. Stat. Sci. 1:297-318.

Heifetz, J.

2002. Coral in Alaska: distribution, abundance, and species associations. Hydrobiologia 471:19-28. Article

Heifetz, J., B. L. Wing, R. P. Stone, P. W. Malecha, and D. L. Courtney.

2005. Corals of the Aleutian Islands. Fish. Oceanogr. 14(suppl. 1):131-138. Article

Hourigan, T. F.

2009. Managing fishery impacts on deep-water coral ecosystems of the USA: emerging best practices. Mar. Ecol. Prog. Ser. 397:333-340. Article

Kim, Y.-J., and C. Gu.

2004. Smoothing spline Gaussian regression: more scalable computation via efficient approximation. J. R. Stat. Soc., Ser. B: Stat. Method. 66:337-356. Article

Knudby, A., E. Kenchington, and F. J. Murillo.

2013. Modeling the distribution of Geodia sponges and sponge grounds in the Northwest Atlantic. PLoS ONE 8(12):e82306. Article

Kotwicki, S., A. DeRobertis, P. von Szalay, and R. Towler. 2009. The effect of light intensity on the availability of walleye pollock (Theragra chalcogramma) to bottom trawl and acoustic surveys. Can. J. Fish. Aquat. Sci. 66:983-994. Article

Krebs, C. J.

1989. Ecological methodology, $2^{\text {nd }}$ ed., 654 p. Harper \& Row, Publs., Inc., New York.

Krieger, K. J.

1993. Distribution and abundance of rockfish determined from a submersible and by bottom trawling. Fish. Bull. 91:87-96.

Krieger, K. J., and D. H. Ito.

1999. Distribution and abundance of shortraker rockfish, Sebastes borealis, and rougheye rockfish, S. aleutianus, determined from a manned submersible. Fish. Bull. 97:264-272.

Krieger, K. J., and B. L. Wing.

2002. Megafauna associations with deepwater corals (Primnoa spp.) in the Gulf of Alaska. Hydrobiologia 471:83-90.

Ladd, C., G. L. Hunt Jr., C. W. Mordy, S. A. Salo, and P. J. Stabeno.

2005. Marine environment of the eastern and central Aleutian Islands. Fish. Oceanogr. 14(suppl. 1):22-38. Article

Laidig, T. E., D. L. Watters, and M. M. Yoklavich.

2009. Demersal fish and habitat associations from visual surveys on the central California shelf. Estuar. Coast. Shelf Sci. 83:629-637. Article

Landis, J. R., and G. G. Koch.

1977. The measurement of observer agreement for categorical data. Biometrics 33:159-174. [Available at website.]

Logerwell, E. A., K. Aydin, S. Barbeaux, E. Brown, M. E. Conners, S. Lowe, J. W. Orr, I. Ortiz, R. Reuter, and P. Spencer. 2005. Geographic patterns in the demersal ichthyofauna of the Aleutian Islands. Fish. Oceanogr. 14(suppl. 1):93-112. Article

Love, M. S., M. H. Carr, and L. Haldorson.

1991. The ecology of substrate-associated juveniles of the genus Sebastes. Environ. Biol. Fish. 30:225-243. Article 
Love, M. S., M. Yoklavich, and L. Thorsteinson. 2002. The rockfishes of the northeast Pacific, 414 p. Univ. California Press, Berkeley, CA.

Malecha, P. W., R. P. Stone, and J. Heifetz. 2005. Living substrate in Alaska: Distribution, abundance, and species associations. Am. Fish. Soc. Symp. 41:289-299.

Manel, S., H. Ceri Williams, and S. J. Ormerod.

2001. Evaluating presence-absence models in ecology: the need to account for prevalence. J. Appl. Ecol. 38:921-931. Article

Maravelias, C. D.

2001. Habitat associations of Atlantic herring in the Shetland area: influence of spatial scale and geographic segmentation. Fish. Oceanogr. 10:259-267. Article

Maravelias, C., and C. Papaconstantinou.

2003. Size-related habitat use, aggregation patterns and abundance of anglerfish (Lophius budegassa) in the Mediterranean Sea determined by generalized additive modelling. J. Mar. Biol. Assoc. U.K. 83:1171-1178. Article

Marliave, J., and W. Challenger.

2009. Monitoring and evaluating rockfish conservation areas in British Columbia. Can. J. Fish. Aquat. Sci. 66:995-1006. Article

Matthews, K. R.

1990. A comparative study of habitat use by young-ofthe-year, subadult, and adult rockfishes on four habitat types in central Puget Sound. Fish. Bull. 88:223-239.

McCullagh, P., and J. A. Nelder.

1989. Generalized linear models, $2^{\text {nd }} e d, 532$ p. Chapman and Hall, London.

O'Brien, L., and P. Rago.

1996. An application of the generalized additive model to groundfish survey data with Atlantic cod off the northeast coast of the United States as an example. NAFO Sci. Counc. Stud. 28:79-95. [Available at website.]

Palof, K. J., J. Heifetz, and A. J. Gharrett.

2011. Geographic structure in Alaskan Pacific ocean perch (Sebastes alutus) indicates limited lifetime dispersal. Mar. Biol. 158:779-792. Article

Palumbi, S. R.

1984. Tactics of acclimation: morphological changes of sponges in an unpredictable environment. Science 225:1478-1480. Article

Paraketsov, I. A.

1963. On the biology of Sebastodes alutus of the Bering Sea. In Soviet fisheries investigations in the northeastern Pacific, part I (P. A. Moiseev, ed.), p. 319327. [Available from U.S. Dep. Commer., Natl. Tech. Inf. Serv., Springfield, VA, as TT67-51203.]

Pearcy, W. G., D. L. Stein, M. A. Hixon, E. K. Pikitch, W. H. Barss, and R. M. Starr.

1989. Submersible observations of deep-reef fishes of Heceta Bank, Oregon. Fish. Bull. 87:955-965.

R Development Core Team.

2011. R: a language and environment for statistical computing. R Foundation for Statistical Computing, Vienna, Austria. [Available from http://www.r-project. org, accessed August, 2011.]

Rand, K. M., and S. A. Lowe.

2011. Defining essential fish habitat for Atka mackerel with respect to feeding within and adjacent to Aleutian Islands trawl exclusion zones. Mar. Coast. Fish. 3:21-31. Article
Rooper, C. N.

2008. An ecological analysis of rockfish (Sebastes spp.) assemblages in the North Pacific Ocean along broadscale environmental gradients. Fish. Bull. 106:1-11.

Rooper, C. N., and J. L. Boldt.

2005. Distribution of juvenile Pacific ocean perch $S e$ bastes alutus in the Aleutian Islands in relation to benthic habitat. Alaska Fish. Res. Bull. 11:102-112.

Rooper, C. N., J. L. Boldt, and M. Zimmermann.

2007. An assessment of juvenile Pacific ocean perch (Sebastes alutus) habitat use in a deepwater nursery. Estuar. Coast. Shelf Sci. 75:371-380. Article

Rooper, C. N., G. R. Hoff, and A. De Robertis.

2010. Assessing habitat utilization and rockfish (Sebastes spp.) biomass on an isolated rocky ridge using acoustics and stereo image analysis. Can. J. Fish. Aquat. Sci. 67:1658-1670. Article

Rooper, C. N., and M. H. Martin.

2009. Predicting presence and abundance of demersal fishes: a model application to shortspine thornyhead Sebastolobus alascanus. Mar. Ecol. Prog. Ser. 379:253-266. Article

2012. Comparison of habitat-based indices of abundance with fishery-independent biomass estimates from bottom trawl surveys. Fish. Bull. 110:21-35.

Rooper, C. N., and M. E. Wilkins.

2008. Data report: 2004 Aleutian Islands bottom trawl survey. NOAA Tech. Memo. NMFS-AFSC-185, 207 p. [Available at website]

Rooper, C. N., M. E. Wilkins, C. S. Rose, and C. Coon.

2011. Modeling the impacts of bottom trawling and the subsequent recovery rates of sponges and corals in the Aleutian Islands, Alaska. Cont. Shelf Res. 31:1827-1834. Article

Ryer, C. H.

1988. Pipefish foraging: effects of fish size, prey size and altered habitat complexity. Mar. Ecol. Prog. Ser. 48:37-45. Article

Ryer, C. H., and B. L. Olla.

1999. Light-induced changes in prey consumption and behavior of two juvenile planktivorous fish. Mar. Ecol. Prog. Ser. 181:41-51. Article

Ryer, C. H., A. W. Stoner, and R. H. Titgen.

2004. Behavioral mechanisms underlying the refuge value of benthic habitat structure for two flatfishes with differing anti-predator strategies. Mar. Ecol. Prog. Ser. 268:231-243. Article

Sathyendranath, S., and T. Platt.

1990. The light field in the ocean: its modification and exploitation by the pelagic biota. Light and life in the sea (P. J. Herring, A. K. Campbell, M. Whitfield, and L. Maddox, eds.) p. 3-18. Cambridge Univ. Press, Cambridge, UK.

Seeb, L. W., and D. R. Gunderson.

1988. Genetic variation and population structure of $\mathrm{Pa}$ cific ocean perch (Sebastes alutus). Can. J. Fish. Aquat. Sci. 45:78-88. Article

Stabeno, P. J., D. G. Kachel, N. B. Kachel, and M. E. Sullivan. 2005. Observations from moorings in the Aleutian Passes: temperature, salinity and transport. Fish. Oceanogr. 14(suppl. 1):39-54. Article

Stabeno, P. J., J. D. Schumacher, and K. Ohtani.

1999. The physical oceanography of the Bering Sea. In Dynamics of the Bering Sea: a summary of physical, chemical, and biological characteristics, and a synopsis 
of research on the Bering Sea (T. R. Loughlin and K. Ohtani, eds.), p. 1-28. Alaska Sea Grant College Program Rep. AK-SG-99-03. Univ. Alaska, Fairbanks, AK. Article

Stauffer, G.

2004. NOAA protocols for groundfish bottom trawl surveys of the nation's fishery resources. NOAA Tech. Memo. NMFS-F/SPO-65, 205 p. [Available at website.]

Stein, D. L., B. N. Tissot, M. A. Hixon, and W. Barss.

1992. Fish-habitat associations on a deep reef at the edge of the Oregon continental shelf. Fish. Bull. 90:540-551.

Stockhausen, W. T., and A. J. Hermann.

2007. Modeling larval dispersion of rockfish: a tool for marine reserve design? In Biology, assessment, and management of North Pacific rockfishes (J. Heifetz, J. DiCosimo, A. J. Gharrett, M. S. Love, V. M. O'Connell, and R. D. Stanley, eds.), Alaska Sea Grant College Program Rep. AK-SG-07-01. Univ. Alaska, Fairbanks, AK. Article

Stone, R., H. Lehnert, and H. Reiswig.

2011. A guide to the deep-water sponges of the Aleutian Island Archipelago. NOAA Professional Paper NMFS $12,187 \mathrm{p}$.

Stoner, A. W.

1982. The influence of benthic macrophytes on the foraging behavior of pinfish, Lagodon rhomboides (Linnaeus). J. Exp. Mar. Biol. Ecol. 58:271-284. Article

Swift, J., and K. Aagaard.

1976. Upwelling near Samalga Pass. Limnol. Oceanogr. 21:399-408. Article

Tissot, B. N., M. M. Yoklavich, M. S. Love, K. York, and M. Amend.

2006. Benthic invertebrates that form habitat on deep banks off southern California, with special reference to deep sea coral. Fish. Bull. 104:167-181.

von Szalay, P. G., C. N. Rooper, N. W. Raring, and M. H. Martin.

2011. Data report: 2010 Aleutian Islands bottom trawl survey. NOAA Tech. Memo. NMFS-AFSC-215, 153 p. [Available at website.]

Wakabayashi, K., R. G. Bakkala, and M. S. Alton.

1985. Methods of the U.S.-Japan demersal trawl surveys. In Results of cooperative U.S.-Japan ground- fish investigations in the Bering Sea during May-August 1979 (R. G. Bakkala and K. Wakabayashi eds.), p. 7-29. INPFC Bull. 44. [Available at website.]

Wassenberg, T. J., G. Dews, and S. D. Cook.

2002. The impact of fish trawls on megabenthos (spong-

es) on the north-west shelf of Australia. Fish. Res. 58: 141-151. Article

Weinberg, K. L., and S. Kotwicki.

2008. Factors influencing net width and sea floor contact of a survey bottom trawl. Fish. Res. 93:265279. Article

Wing, B. L., and D. R. Barnard. 2004. A field guide to Alaskan corals. NOAA Tech. Memo. NMFS-AFSC 146, 67 p. [Available at website.]

Withler, R. E., T. D. Beacham, A. D. Schulze, L. J. Richards, and K. M. Miller.

2001. Co-existing populations of Pacific ocean perch, Sebastes alutus, in Queen Charlotte Sound, British Columbia. Mar. Biol. 139:1-12. Article

Wood, S. N.

2006. Generalized additive models: an introduction with R, 392 p. Chapman and Hall/CRC, Boca Raton, FL.

Yoklavich, M. M., H. G. Greene, G. M. Cailliet, D. E. Sullivan,

R. N. Lea, and M. S. Love.

2000. Habitat associations of deep-water rockfishes in a submarine canyon: an example of a natural refuge. Fish. Bull. 98:625-641.

Zar, J. H.

1984. Biostatistical analysis, $2^{\text {nd }}$ ed., 718 p. PrenticeHall, Inc., Englewood, NJ.

Zenger, H. H., Jr.

2004. Data report: 2002 Aleutian Islands bottom trawl survey. NOAA Tech. Memo. NMFS-AFSC-143, 247 p. [Available at Website.]

Zimmermann, M.

2003. Calculation of untrawlable areas within boundaries of a bottom trawl survey. Can. J. Fish. Aquat. Sci. 60:657-669. Article

Zuur, A. F., E. N. Ieno, N. J. Walker, A. A. Saveliev, and G. M. Smith.

2009. Mixed effects models and extensions in ecology with R, 596 p. Springer, New York. 